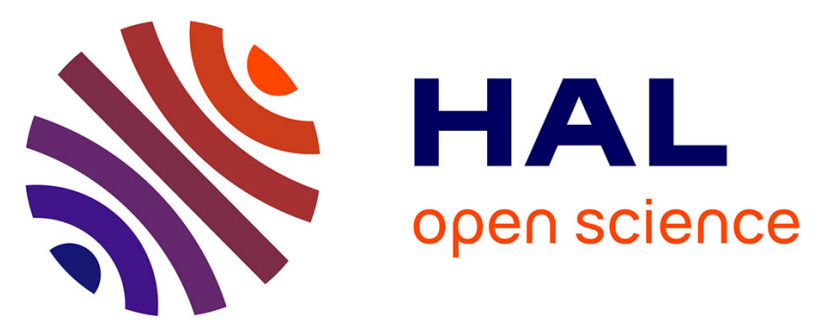

\title{
Chemical Synthesis of TFF3 Reveals Novel Mechanistic Insights and a Gut-Stable Metabolite
}

\author{
Nayara Braga Emidio, Rajeshwari Meli, Hue Tran, Hayeon Baik, Séverine \\ Morisset-Lopez, Alysha Elliott, Mark Blaskovich, Sabrina Spiller, Annette \\ Beck-Sickinger, Christina Schroeder, et al.
}

\section{To cite this version:}

Nayara Braga Emidio, Rajeshwari Meli, Hue Tran, Hayeon Baik, Séverine Morisset-Lopez, et al.. Chemical Synthesis of TFF3 Reveals Novel Mechanistic Insights and a Gut-Stable Metabolite. Journal of Medicinal Chemistry, 2021, 64 (13), pp.9484-9495. 10.1021/acs.jmedchem.1c00767 . hal-03335490

\author{
HAL Id: hal-03335490 \\ https://hal.science/hal-03335490
}

Submitted on 21 Nov 2021

HAL is a multi-disciplinary open access archive for the deposit and dissemination of scientific research documents, whether they are published or not. The documents may come from teaching and research institutions in France or abroad, or from public or private research centers.
L'archive ouverte pluridisciplinaire HAL, est destinée au dépôt et à la diffusion de documents scientifiques de niveau recherche, publiés ou non, émanant des établissements d'enseignement et de recherche français ou étrangers, des laboratoires publics ou privés. 


\title{
Chemical Synthesis of TFF3 Reveals Novel Mechanistic Insights and a Gut-Stable Metabolite
}

\author{
3 Nayara Braga Emidio, Rajeshwari Meli, Hue N. T. Tran, Hayeon Baik, Séverine Morisset-Lopez, \\ 4 Alysha G. Elliott, Mark A. T. Blaskovich, Sabrina Spiller, Annette G. Beck-Sickinger, \\ s Christina I. Schroeder, and Markus Muttenthaler*
}

Cite This: https://doi.org/10.1021/acs.jmedchem.1c00767

Read Online

SI Supporting Information

6 ABSTRACT: TFF3 regulates essential gastro- and neuroprotective 7 functions, but its molecular mode of action remains poorly understood. 8 Synthetic intractability and lack of reliable bioassays and validated receptors 9 are bottlenecks for mechanistic and structure-activity relationship studies. 10 Here, we report the chemical synthesis of TFF3 and its homodimer via native 11 chemical ligation followed by oxidative folding. Correct folding was 12 confirmed by NMR and circular dichroism, and TFF3 and its homodimer 13 were not cytotoxic or hemolytic. TFF3, its homodimer, and the trefoil 14 domain (TFF3 ${ }_{10-50}$ ) were susceptible to gastrointestinal degradation, 15 revealing a gut-stable metabolite $\left(\mathrm{TFF}_{7-54} ; t_{1 / 2}>24 \mathrm{~h}\right.$ ) that retained its 16 trefoil structure and antiapoptotic bioactivity. We tried to validate the 17 putative TFF3 receptors CXCR4 and LINGO2, but neither TFF3 nor its 18 homodimer displayed any activity up to $10 \mu \mathrm{M}$. The discovery of a gut-stable

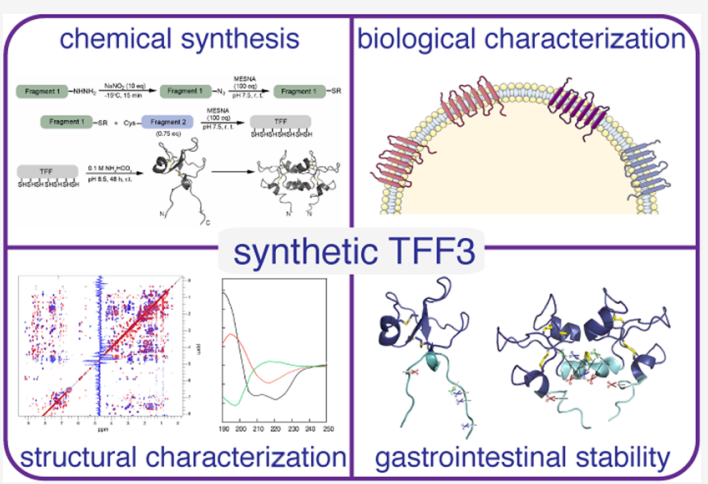
19 bioactive metabolite and reliable synthetic accessibility to TFF3 and its analogues are cornerstones for future molecular probe 20 development and structure-activity relationship studies.

\section{1}

22 The trefoil factor family (TFF) comprises three disulfide-rich 23 peptides (TFF1, TFF2, TFF3) that are abundantly secreted in 24 the gastrointestinal tract where they regulate gut homeostasis 25 by promoting gut protection and repair. ${ }^{1-5}$ They are also 26 expressed in mucosal tissues outside the gut, including in the 27 respiratory tract, urinary tract, uterus, eyes, and salivary glands, 28 where they have similar mucosal repair and protective 29 functions. TFF peptides have also been observed in human 30 breast milk and the brain, ${ }^{1,6,7}$ and have been implicated in 31 cancer development. ${ }^{1,8,9}$

32 TFF3 is highly expressed in the gastrointestinal mucosa, 33 particularly in the small intestine and colon, where it protects, 34 maintains, and repairs the gastrointestinal tract. ${ }^{4,10-17}$ In the 35 central nervous system (CNS), TFF3 is secreted by neurons 36 and regulates physiological effects such as neuroinflammation ${ }^{18}$ 37 and behavioral processes including learning and memory ${ }^{19}$ and 38 depression. $^{20,21}$ The anti-inflammatory effects of TFF3 on 39 microglia cells (reduced expression and secretion of pro40 inflammatory cytokines) and its capacity to mitigate ischemic 41 cerebral injuries by reducing cell death via suppression of 42 caspase- 3 activity further support TFF3's neuroprotective role 43 in the CNS. ${ }^{18,22}$

44 TFF3 derives from a 94-residue long precursor protein that 45 comprises a 35-residue-long signal peptide followed by the 5946 residue-long TFF3 sequence. ${ }^{23}$ The mature secreted and folded TFF3 peptide $\left(\right.$ TFF $_{1-59}$ ) contains a highly conserved 47 trefoil domain (TFF3 $3_{10-50}$ ) that also defines the other members 48 of the TFF. ${ }^{3,24}$ The trefoil domain contains six conserved 49 cysteine residues $\left(\mathrm{CX}_{9-10} \mathrm{CX}_{9} \mathrm{CX}_{4} \mathrm{CCX}_{10} \mathrm{C}\right.$ motif) forming 50 three intrachain disulfide bonds in the configuration $\mathrm{Cys}^{\mathrm{I}}{ }^{-\mathrm{V}}, 51$ Cys ${ }^{\mathrm{II}-\mathrm{IV}}$, and Cys ${ }^{\mathrm{II}-\mathrm{VI}}$.,24 This disulfide bond arrangement 52 creates a compact three-loop structure resembling a trefoil 53 shape, which is considered to be metabolically stable based on 54 TFF3's functional role in the gastrointestinal tract. ${ }^{3,24,25}$ Its 55 gastrointestinal stability has, however, not been systematically 56 investigated, and some reports indicate that TFF3 might not be 57 that stable. ${ }^{26-28}$

TFF3 also has an additional $C$-terminal cysteine residue 59 $\left(\mathrm{Cys}{ }^{\mathrm{VII}}\right.$ ) located outside the trefoil domain, which enables the 60 formation of covalent homo- or heterodimers (e.g., with the 61 mucus-associated $\mathrm{Fc}$ fragment of IgG Fc binding protein, 62 FCGBP). ${ }^{29,30}$ TFF3-FCGBP's function remains unknown, but 63 it is hypothesized to act as a TFF3 reservoir. ${ }^{29}$ Although the 64 TFF3 homodimer is only present in relatively small 65

Received: April 28, 2021 

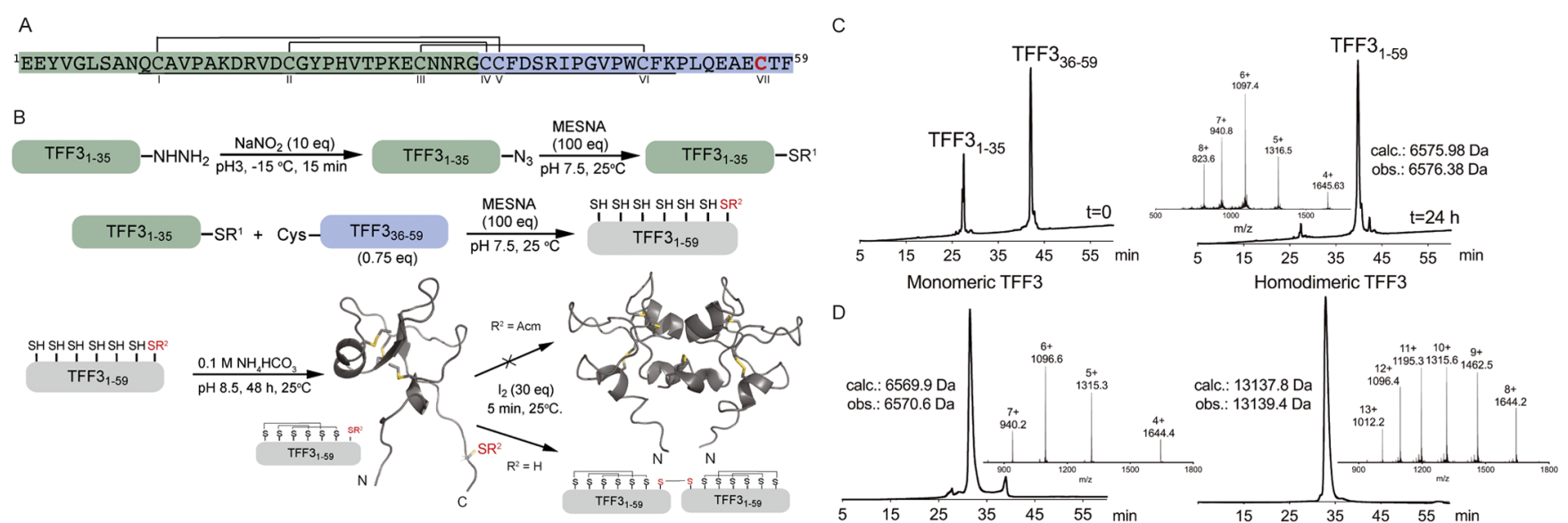

Figure 1. Synthesis of TFF3 and its homodimer. (A) TFF3 sequence and disulfide bond connectivity. Sequence highlighted in green and blue represents the $\mathrm{N}$ - and $\mathrm{C}$-terminal fragments used for native chemical ligation, respectively, with $\mathrm{Cys}^{57}$ (red) used for dimerization. The trefoil domain is underlined. (B) Synthetic strategy used to produce TFF3 and its homodimer. Highlighted in gray is full-length TFF3. (C) Ligation reaction at time $0 \mathrm{~h}$ (left) and $24 \mathrm{~h}$ (right). (D) Analytical RP-HPLC chromatogram and MS of folded TFF3 monomer (left) and homodimer (right). TFF3 monomer displays a two-peak RP-HPLC profile due to its conformational complexity (see also Figure S3). TFF3 PDB: 1E9T; TFF3 homodimer PDB: 1PE3.

66 quantities, $^{29}$ it is more potent than its monomeric counterpart 67 in promoting cell motility. ${ }^{31,32}$ Additionally, only the 68 homodimer but not the monomer displays protective effects 69 when luminally administrated in an experimental model of 70 colitis. $^{32}$

71 TFF3 can induce several biological effects (i.e., antiapopto72 tis, ${ }^{33,34}$ cell migration, ${ }^{35-37}$ and anti-inflammatory effects ${ }^{38}$ ), 73 but its mode of action and target receptors have not been fully 74 elucidated nor validated. ${ }^{30}$ TFF3 was recently described as a 75 natural ligand of the leucine-rich repeat receptor and nogo76 interacting protein 2 (LINGO2), ${ }^{38}$ with TFF3-LINGO2 77 interaction mediating intestinal wound healing and immunity 78 through enhanced epidermal growth factor receptor (EGFR) 79 signaling. ${ }^{38}$ Another putative receptor is the chemokine 80 receptor type 4 (CXCR4), through which TFF3 might 81 mediate cell migration via an ERK1/2-independent signaling 82 pathway. ${ }^{39}$

83 TFF3 is considered a promising therapeutic lead, especially 84 for disorders requiring epithelial protection, repair, or 85 restitution, such as inflammatory bowel diseases (IBD) and 86 nonsteroidal anti-inflammatory drug-induced gastritis. ${ }^{30}$ Its 87 therapeutic potential is supported by promising preclini$88 \mathrm{cal}^{11,40-42}$ and clinical studies. ${ }^{30,43,44}$ TFF3 is currently 89 obtained either through recombinant production in Escherichia 90 coli, Saccharomyces cerevisiae, or human embryonic kidney 293 ${ }_{91}$ (HEK-293) cells, ${ }^{45-47}$ or through purification from milk ${ }^{48}$ or 92 meconium. ${ }^{49}$ These approaches are however not ideal for drug 93 target discovery, where advanced probe development is 94 required, nor for drug development efforts where the 95 incorporation of unnatural amino acids, reporter tags, or 96 conjugation handles at specific positions is often required. 97 Chemical synthesis would allow for such regiospecific control 98 and incorporation of unnatural amino acids, thereby 99 considerably facilitating mechanistic studies and therapeutic 100 development. We thus set out to establish a synthetic strategy 101 to produce TFF3 and its homodimer reliably and in sufficient 102 quantities to deliver new insights into their pharmacology, 103 toxicity, and metabolic stability.

\section{RESULTS}

Chemical Synthesis of TFF3, TFF3( $\left.\mathrm{C}^{57} \mathrm{Acm}\right)$, and TFF3 105 Homodimer. Single-chain assembly of full-length TFF3 $3_{1-59} 106$ was not successful due to difficult sequence sections. We 107 therefore switched to a two-fragment native chemical ligation 108 (NCL) approach using the Fmoc-SPPS (9-fluorenylmethylox- 109 ycarbonyl-solid-phase peptide synthesis)-compatible hydrazide 110 strategy (Figure 1). ${ }^{50}$ We split the TFF3 sequence into an $N$ - $111 \mathrm{fl}$ terminal TFF $3_{1-35}$ fragment with a glycine at the ligation site 112 (faster ligation due to less steric hindrance) and a C-terminal 113 $\mathrm{TFF}_{36-59}$ fragment with an $\mathrm{N}$-terminal cysteine residue at the 114 ligation site (Figure 1A). We synthesized TFF3 ${ }_{1-35}$ with a $C$ - 115 terminal hydrazide function $(\sim 15 \%$ yield after purification $)$ on 116 a freshly prepared 2-Cl-(Trt)- $\mathrm{NHNH}_{2}$ resin and $\mathrm{TFF}_{36-59} 117$ with a $C$-terminal acid ( $\sim 20 \%$ yield after purification) using a 118 Phe-Wang PS resin. We activated $\mathrm{TFF}_{1-35}-\mathrm{NHNH}_{2}$ with 119 $\mathrm{NaNO}_{2}$ to form the $C$-terminal acyl azide followed by 120 conversion of the azide into a thioester through addition of 121 sodium 2-mercaptoethanesulfonate (MESNA) (Figure 1B). ${ }^{50} 122$ We then ligated the two fragments (TFF3 $3_{1-35}$ and $\mathrm{TFF}_{36-59}$ ) 123 to produce the linear and fully reduced TFF $3_{1-59}$ and purified it 124 on a $\mathrm{C}_{18}$-RP-HPLC column ( $\sim 57 \%$ ligation yield) (Figure 125 $1 \mathrm{~B}, \mathrm{C})$.

After oxidative folding ( $0.1 \mathrm{M}$ ammonium bicarbonate, $\mathrm{pH} 127$ 8.5, $48 \mathrm{~h}$; Figure S1), we purified TFF3 on a $\mathrm{C}_{5}$-RP-HPLC 128 column (Figure 1D, left). The TFF3 homodimer was produced 129 via the formation of an intermolecular disulfide bond of 130 unprotected Cys ${ }^{\mathrm{VII}}$ (residue 57) through treatment with iodine 131 $\left(2 \mathrm{~min}\right.$ ) followed by $\mathrm{C}_{5}$-RP-HPLC purification (Figure 1D, 132 right; $60 \%$ yield). Since dimerization of TFF3 with the 133 unprotected Cys ${ }^{\mathrm{VII}}$ residue was observed in aqueous solvents at 134 $\mathrm{pH}>7$, we also synthesized a TFF3 analogue with Cys ${ }^{\text {VII }} 135$ protected with an acetamidomethyl (Acm) group (TFF3- 136 $\left.\left(\mathrm{C}^{57} \mathrm{Acm}\right)\right)$ to prevent dimerization and to ensure clear 137 functional distinction between monomeric and homodimeric 138 TFF3 in further studies (Figure S1).

139

Folded TFF3, whether with Cys ${ }^{\mathrm{VII}}$ protected or not, 140 displayed a two-peak profile on analytical HPLC, with each 141 peak having the correct mass (Figures 1D and S2). When these 142 peaks were independently collected and reinjected, the same 143 

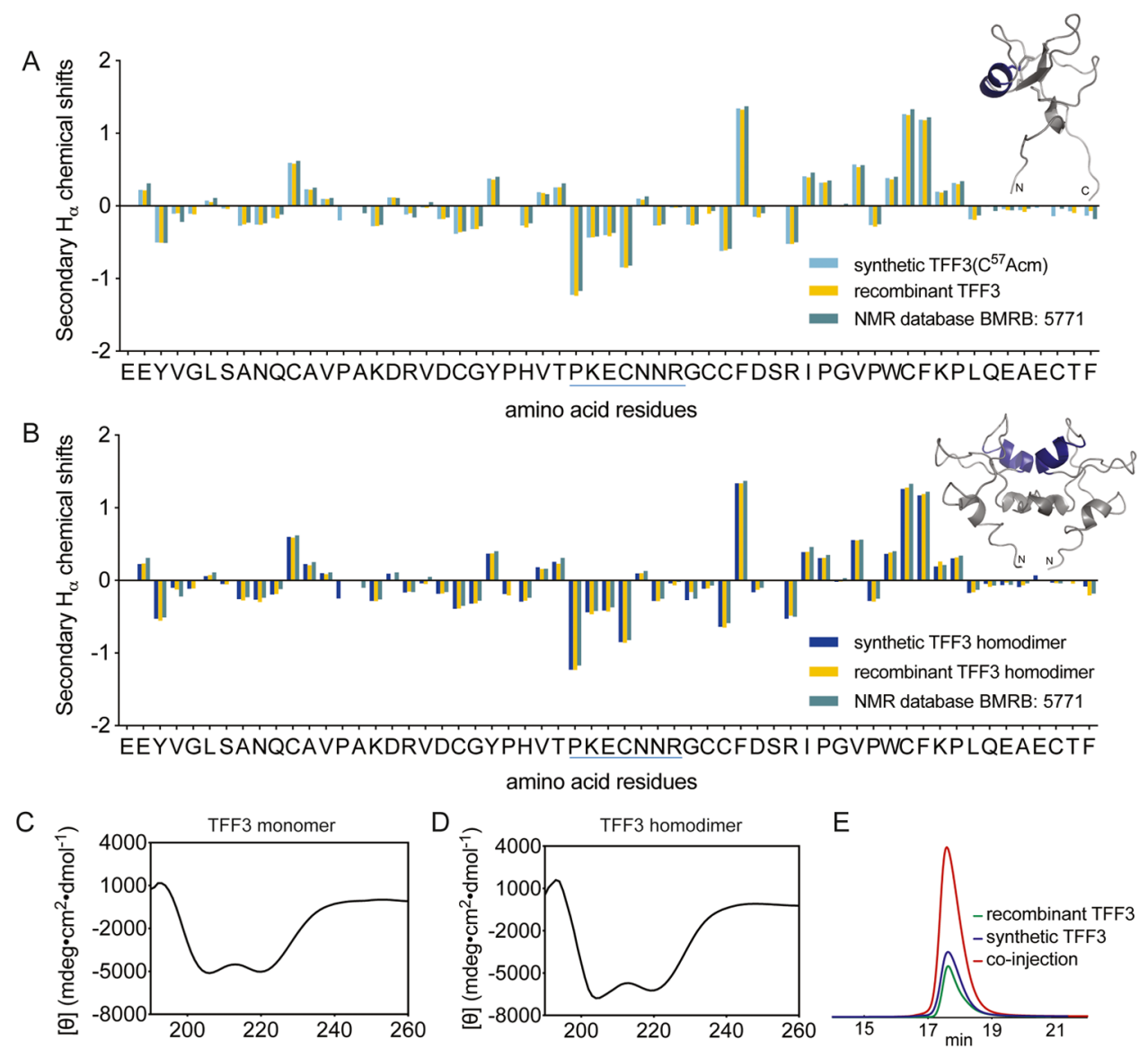

Figure 2. Comparison of secondary $\mathrm{H} \alpha$ chemical shifts of (A) TFF3 $\left(\mathrm{C}^{57} \mathrm{Acm}\right)$ and (B) TFF3 homodimer produced by chemical synthesis with recombinant homologues and reported values from the Biological Magnetic Resonance Data Bank (BMRB: 5771). Secondary H $\alpha$ chemical shifts were determined by subtracting the shifts observed in random coil peptides from the shifts determined from the two-dimensional (2D) NMR analysis. ${ }^{57}$ An $\alpha$-helical region is highlighted in blue in the sequence and NMR structure. CD spectra of synthetic (C) TFF3(C ${ }^{57}$ Acm $)$ and (D) TFF3 homodimer. (E) Co-elution of synthetic and recombinant TFF3 homodimer (1:2 ratio) on a $\mathrm{C}_{3}$-RP-HPLC (1\% gradient).

144 two-peak profile was observed (Figure S3), confirming that 145 both peaks belong to TFF3. This is consistent with the 146 conformational complexity of $\mathrm{TFF}^{45}$ and an effect commonly 147 observed with similarly complex peptides and proteins, 148 including TFF $1 . .^{51-55}$

149 Synthetic TFF3 and TFF3 Homodimer Have the ${ }_{150}$ Correct Fold. We characterized folded TFF3 and TFF3 151 homodimer by nuclear magnetic resonance (NMR) and 152 circular dichroism (CD) experiments and compared them 153 with the structures of recombinant TFF3 and TFF3 154 homodimer. ${ }^{24,56}$ The $\mathrm{H} \alpha$ chemical shifts of $\mathrm{TFF} 3\left(\mathrm{C}^{57} \mathrm{Acm}\right)$ 155 and TFF3 homodimer were assigned using total correlated 156 spectroscopy (TOCSY) and nuclear Overhauser effect spec157 troscopy (NOESY). Secondary chemical shifts were deter158 mined by subtracting random coil shifts from the $\mathrm{H} \alpha$ chemical 159 shifts. ${ }^{57}$ Comparison of the secondary chemical shift of 160 synthetic and recombinantly expressed TFF3 (Figure 2A), as 161 well as those of the corresponding homodimers (Figure 2B), 162 confirmed the correct fold. ${ }^{24,56} \mathrm{CD}$ analysis of synthetic TFF3 163 indicated the presence of an $\alpha$-helical structure characterized 164 by negative bands at 222 and $208 \mathrm{~nm}$ and a positive band at $165193 \mathrm{~nm}$ (Figure 2C,D). This aligned well with the structural 166 information obtained from recombinant TFF3 provided by Dr. 167 Lars Thim (Novo Nordisk A/S) ${ }^{45}$ that has a well-defined $\alpha$ 168 helix in loop 2. A co-elution study of synthetic and recombinant TFF3 homodimer further confirmed the NMR 169 and $\mathrm{CD}$ results (Figure $2 \mathrm{E}$ ).

TFF3 and TFF3 Homodimer Reduce Apoptosis of 171 Neuroblastoma Cells. The antiapoptotic activity of TFF3 172 was reported in cerebral ischemia. ${ }^{22}$ We therefore evaluated 173 the capacity of TFF3 and its homodimer to reduce etoposide- 174 induced cell death, by inhibiting caspase-3/7, in a neuro- 175 blastoma cell line (SH-SY5Y). TFF3 and its homodimer (10 176 $\mu \mathrm{M})$ induced a statistically significant $(p<0.05)$ reduction in 177 cell death (Figure 3A).

TFF3 and TFF3 Homodimer Are Not Cytotoxic or 179 Hemolytic. Considering the therapeutic potential of TFF3, it 180 was important to determine any cytotoxic and hemolytic 181 effects early on to avoid problems in later stages of drug 182 development. We therefore assessed cytotoxicity on HEK-293 183 cells and hemolytic effects in human erythrocytes. We treated 184 the cells with TFF3 $\left(\mathrm{C}^{57} \mathrm{Acm}\right)$ and TFF3 homodimer and used 185 resazurin, a blue dye that produces strong fluorescence when 186 reduced by living cells, as the readout of the number of viable 187 cells. $^{60}$ In the hemolytic assay, we evaluated hemoglobin 188 release, an indicator of erythrocyte lysis, upon exposure to the 189 peptides. Neither TFF3 $\left(\mathrm{C}^{57} \mathrm{Acm}\right)$ nor TFF3 homodimer 190 displayed any cytotoxic or hemolytic effects at the concen- 191 trations of up to $\sim 25 \mu \mathrm{M}$ (Figure $3 \mathrm{~B}, \mathrm{C}$ ). in COS-7 Cells Overexpressing the Receptor. CXCR4 is a 194 
A

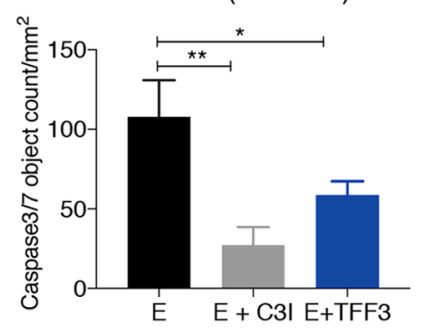

D

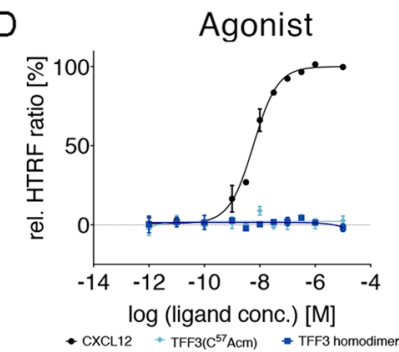

TFF3 homodimer
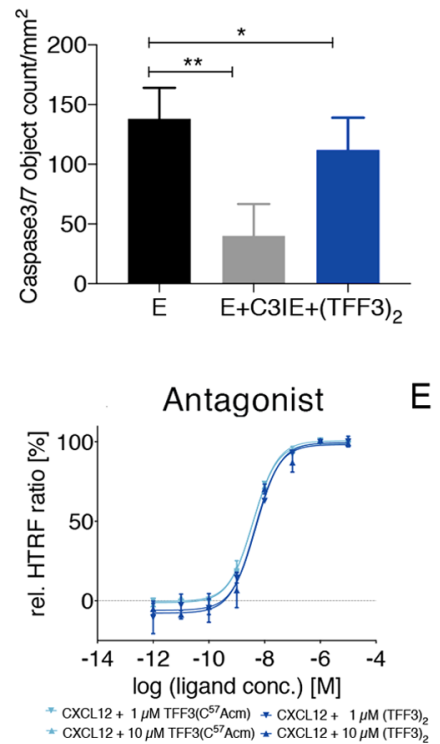

B

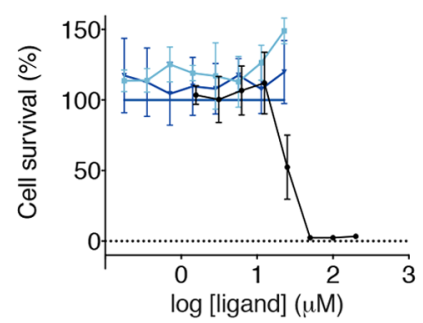

$-\mathrm{TFF} 3\left(\mathrm{C}^{57} \mathrm{Acm}\right)-\mathrm{TFF} 3$ homodimer $*$ Tamoxifen

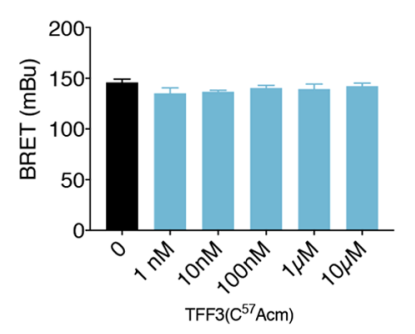

C

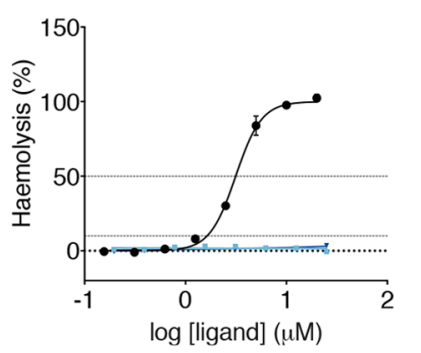

- TFF3(C $\left.{ }^{57} \mathrm{Acm}\right)-$ TFF3 homodimer $\bullet$ Melittin

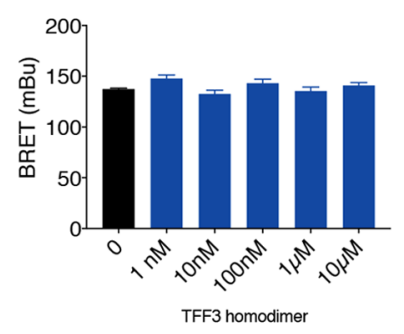

Figure 3. Biological characterization of TFF3 $\left(\mathrm{C}^{57} \mathrm{Acm}\right)$ and TFF3 homodimer. (A) Cell death was induced with etoposide (10 $\left.\mu \mathrm{M}\right)$, and cells were treated with $10 \mu \mathrm{M}$ of TFF3. Etoposide and TFF3 were added at the same time. Caspase-3/7 activity was measured after 6 h. The results are expressed (mean \pm standard error of the mean (SEM)) of $n \geq 3$ independent experiments as the number of green fluorescent caspase-3/7 active objects generated by caspase-3/7 reagent added in media. Z-DEVD-FMK ( $50 \mu \mathrm{M}$; caspase-3 inhibitor) was used as the positive control. E: etoposide, E + C3I: etoposide + caspase-3 inhibitor. One-way analysis of variance (ANOVA) followed by Dunnett correction was performed to assess differences between treated cells and etoposide only. $*_{p}<0.05, * * p<0.01$. (B) TFF3 effect on the viability of HEK-293 cells after 20 h. Tamoxifen was used as a positive control for cell growth inhibition. Data are representative of two independent experiments shown as mean \pm SEM. (C) Hemolytic activity of TFF3 after $1 \mathrm{~h}$ on erythrocytes. Melittin was used as a positive hemolytic control. Data are representative of two independent experiments shown as mean \pm SEM. (D) Effect on CXCR4. Agonistic or antagonistic effects were assessed by the IP1 accumulation assay obtained through homogeneous time-resolved fluorescence (HTRF). CXCL12 was added for antagonistic studies after a 5 min preincubation of TFF3 $\left(\mathrm{C}^{57} \mathrm{Acm}\right)$ or homodimer. For agonistic evaluation, all compounds were used individually for stimulation in the given concentration range. ${ }^{58}$ Neither TFF3 $\left(\mathrm{C}^{57} \mathrm{Acm}\right)$ nor TFF3 homodimer were able to activate or inhibit the signal transduction of CXCR4 at concentrations up to $10 \mu \mathrm{M}$, indicating that these peptides are neither agonists nor antagonists at this receptor. The results are expressed as mean \pm SEM of $n \geq 2$ independent experiments. (E) Effect on LINGO2. HEK-293 coexpressing LINGO2-YFP and LINGO2-Rluc were stimulated with increasing amounts of TFF3 $\left(\mathrm{C}^{57} \mathrm{Acm}\right)$ and TFF3 homodimer $(1 \mathrm{nM}-10 \mu \mathrm{M})$, but no significant increase in the bioluminescence resonance energy transfer (BRET) signal was observed. No ligand able to alter LINGO2 dimerization is known; therefore, no positive control could be used. ${ }^{59}$ Results are expressed as mean \pm SEM for $n=4$. One-way ANOVA followed by Dunnett correction was performed to assess differences between treated and nontreated cells.

195 member of the G protein-coupled receptor (GPCR) family ${ }^{58}$ 196 and proposed as a target receptor for TFF3 to mediate wound 197 healing. ${ }^{30,39} \mathrm{We}$ therefore pharmacologically characterized 198 TFF3 $\left(\mathrm{C}^{57} \mathrm{Acm}\right)$ and TFF3 homodimer at CXCR4. We used 199 a chimeric $\mathrm{G} \alpha_{\mathrm{iq}}$ protein to switch the pathway to the $\mathrm{G} \alpha_{\mathrm{q}}$ 200 signaling, which leads to the activation of the phospholipase 201 and allows measurement of CXCR4 activation through the 202 production of inositol 1 phosphate (IP1). ${ }^{61-63}$ We measured 203 IP1 accumulation upon stimulation with TFF3 and TFF3 204 homodimer in fibroblast-like COS-7 cells transiently trans205 fected with CXCR4. ${ }^{58}$ This is a competitive immunoassay, 206 based on the HTRF technology, where native IP1 produced by 207 cells compete with labeled IP1 (acceptor) for binding to anti208 IP1-cryptate (donor). The specific signal (i.e., Förster 209 resonance energy transfer, FRET) is inversely proportional to 210 the concentration of IP1 in the sample. The calculation of the 211 fluorescence ratio eliminates possible medium interferences. ${ }^{64}$ $212 \mathrm{TFF} 3\left(\mathrm{C}^{57} \mathrm{Acm}\right)$ and TFF3 homodimer were tested alone or 213 in combination with C-X-C motif chemokine 12 (CXCL12), 214 the natural CXCR4 ligand, ${ }^{58}$ to assess TFF3's potential to act 215 as a CXCR4 agonist or antagonist. Neither TFF3 $\left(\mathrm{C}^{57} \mathrm{Acm}\right)$ 216 nor TFF3 homodimer activated CXCR4 at concentrations up 217 to $10 \mu \mathrm{M}$ in contrast to the positive control CXCL12 $\left(\mathrm{EC}_{50}\right.$ $2185.9 \mathrm{nM}$ ) (Figure 3D). The $\mathrm{EC}_{50}$ of $\mathrm{CXCL12}$ was also not affected by TFF3 or TFF3 homodimer (up to $10 \mu \mathrm{M}$ ), 219 suggesting that these peptides are also not antagonists (Figure 220 3D).

TFF3 and TFF3 Homodimer Do Not Activate LINGO2 222 in BRET Assay. LINGO2 has also been put forward as a 223 potential TFF3 receptor. $^{38}$ We thus evaluated whether 224 TFF3 $\left(\mathrm{C}^{57} \mathrm{Acm}\right)$ or TFF3 homodimer could disturb LINGO2 225 dimerization via a bioluminescence resonance energy transfer 226 (BRET) assay. This method allows the study of protein 227 interactions using energy transfer between a light-emitting 228 enzyme and a fluorescent acceptor protein. ${ }^{65}$ LINGO2 fused 229 with Renilla luciferase (Rluc; protein donor) or yellow 230 fluorescent protein (YFP; protein acceptor) were co-expressed 231 in HEK-293 cells and BRET signal detected after adding the 232 luminescent substrate coelenterazine. We observed a strong 233 BRET signal under basal condition, demonstrating the capacity 234 of LINGO2 to form dimers, as already described. ${ }^{59}$ We then 235 evaluated whether the TFF3 constructs could promote changes 236 of this basal BRET signal by inducing conformational change 237 within the dimers and/or change the dimerization state of 238 LINGO2. However, no statistically significant $(p>0.05) 239$ modification of BRET signal was observed following 240 stimulation of HEK-293 cells coexpressing LINGO2-YFP 241 and LINGO2-Rluc with TFF3 $\left(\mathrm{C}^{57} \mathrm{Acm}\right)$ or TFF3 homodimer 242 


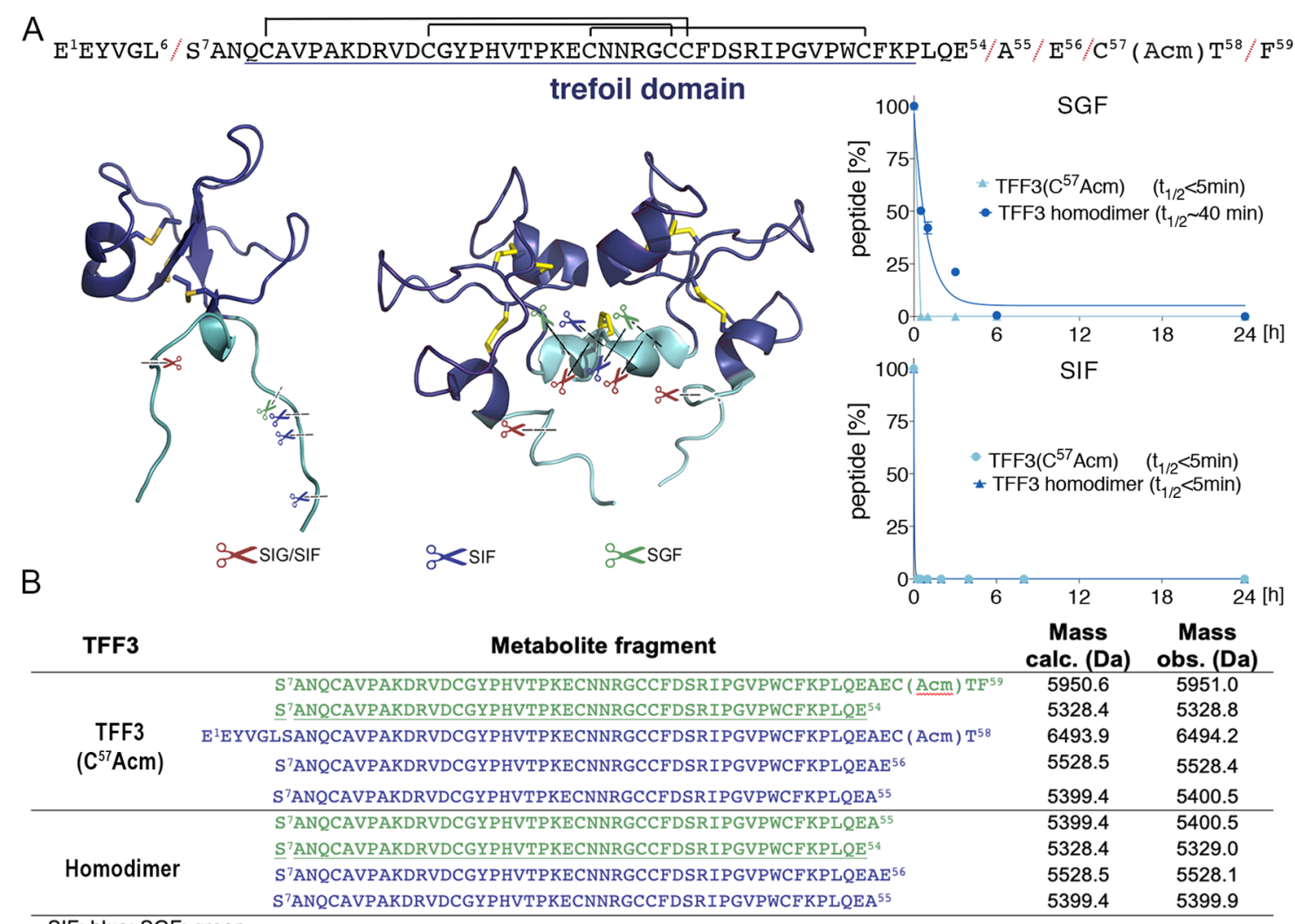

SIF: blue; SGF: green
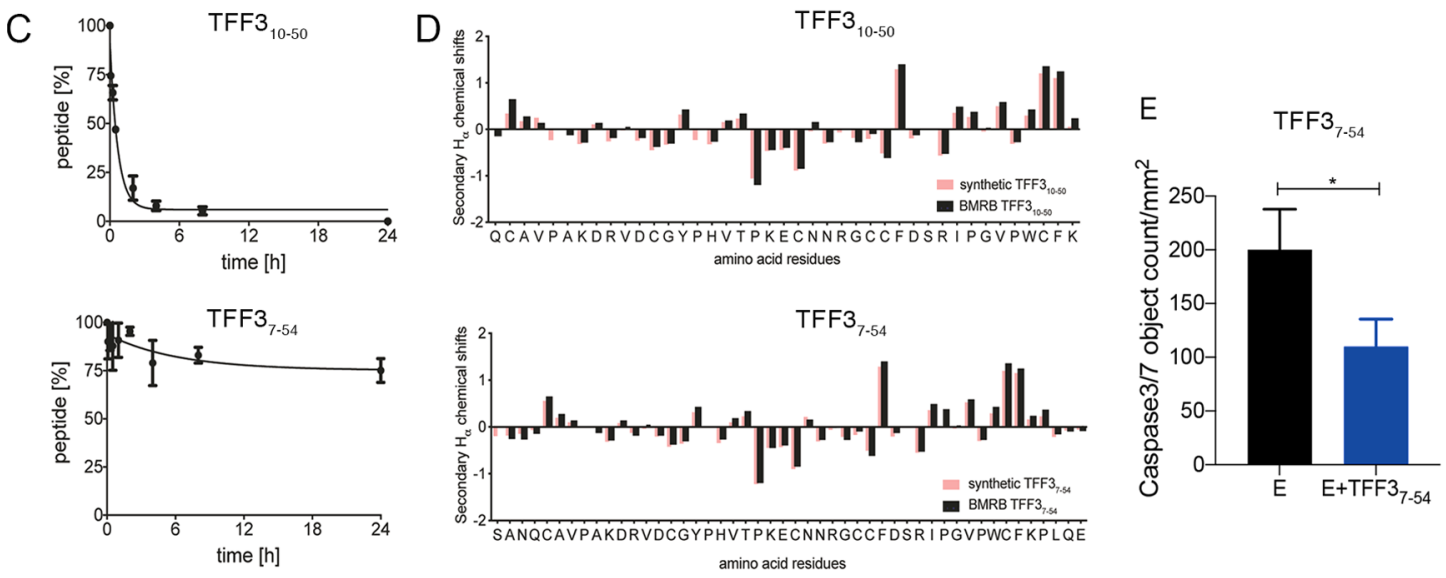

Figure 4. Identification and characterization of a stable and bioactive TFF3 metabolite $\left(\mathrm{TFF} 3_{7-54}\right)$. (A) The observed cleavage sites are highlighted in the three-dimensional structure and linear sequence of TFF3. The trefoil domain is underlined and displayed in blue in the sequence and NMR structure. (B) A table listing the observed fragments including their masses. The shortest stable metabolite $\left(\mathrm{TFF}_{7-54}\right)$ is underlined. $(\mathrm{C}) \mathrm{Intestinal}$ stability of the trefoil domain TFF $3_{10-50}$ and the gut-stable metabolite TFF $3_{7-54}$. (D) Comparison of the secondary H $\alpha$ chemical shifts of TFF3 (BMRB: 5771) and the trefoil domain TFF $3_{10-50}$, and TFF3 (BMRB: 5771) and the gut-stable metabolite TFF3 $3_{7-54}$. Secondary H $\alpha$ chemical shifts were determined by subtracting the shifts observed in random coil peptides from the shifts determined from the $2 \mathrm{D}$ NMR analysis. ${ }^{57}$ (E) Antiapoptotic effects of TFF $3_{7-54}$ on SH-SY5Y cells. E: etoposide. Etoposide and TFF $3_{7-54}$ were added at the same time. Caspase-3/7 activity was measured after $6 \mathrm{~h}$. Results are expressed (mean \pm SEM) of $n \geq 3$ independent experiments as the number of green fluorescent caspase-3/7 active objects generated by caspase- $3 / 7$ reagent added in media. One-way ANOVA followed by Dunnett correction was performed to assess differences between treated cells and etoposide only. ${ }^{*} p<0.05, * *<0.01$.

243 at any of the tested concentrations $(0.1-10 \mu \mathrm{M})(p>0.05)$ 244 (Figure 3E).

245 Gastrointestinal Stability Assays Revealed a Stable 246 and Bioactive TFF3 Metabolite. TFF3 is often considered 247 metabolically stable due to its rigid disulfide-rich structure and 248 function in the gut. ${ }^{3}$ However, no systematic gut stability 249 studies have been carried out and some reports indicate that 250 TFF3 is not fully resistant to proteases. For example, only $15 \%$ 251 of intravenously injected iodine-labeled TFF3 homodimer in rats was recovered from urine after $24 \mathrm{~h}^{26}$ TFF3 homodimer 252 was also degraded in the terminal parts of the large intestine ${ }^{27} 253$ and truncated at the C-terminal Phe ${ }^{59}$ in human saliva. ${ }^{28}$ It was 254 thus important to characterize TFF3's gastrointestinal stability 255 in more detail, particularly considering that studies often rely 256 on the use of sodium dodecyl sulfate (SDS) gels and 257 antibodies to identify and characterize TFF3, where 258 truncations can easily be missed. ${ }^{48,49,66}$ 
260 We exposed TFF3 $\left(\mathrm{C}^{57} \mathrm{Acm}\right)$ and TFF3 homodimer to 261 simulated gastric fluid (SGF, containing pepsin, $\mathrm{pH} 1.3$ ) and 262 simulated intestinal fluid (SIF, containing pancreatic enzymes, $263 \mathrm{pH} 6.8$ ), and monitored the mixture over $24 \mathrm{~h}$ by analytical 264 RP-HPLC and MS. The $N$ - and $C$-termini of TFF3 and its 265 homodimer were readily truncated in both SGF and SIF 266 (Figure 4A,B). In SGF, TFF3 was cleaved at $\mathrm{Leu}^{6} / \mathrm{Ser}^{7}$ 267 followed by cleavage at $\mathrm{Glu}^{54} / \mathrm{Ala}^{55}\left(t_{1 / 2}<5 \mathrm{~min}\right)$. In SIF, 268 TFF3 was cleaved first at $\mathrm{Thr}^{58} / \mathrm{Phe}^{59}$ followed by cleavage at $269 \mathrm{Leu}^{6} / \mathrm{Ser}^{7}, \mathrm{Glu}^{56} / \mathrm{Cys}^{57}$, and $\mathrm{Ala}^{55} / \mathrm{Glu}^{56}\left(t_{1 / 2}<5 \mathrm{~min}\right)$. TFF3 270 homodimer, in both SGF $\left(t_{1 / 2} \sim 40 \mathrm{~min}\right)$ and SIF $\left(t_{1 / 2}<5\right.$ $271 \mathrm{~min}$ ), was first broken down to monomeric TFF3 through 272 simultaneous cleavage at $\mathrm{Leu}^{6}$ and $\mathrm{Glu}^{54}$ or $\mathrm{Ala}^{55}$, eventually 273 leading to the same metabolites as TFF3 (Figure 4B). 274 Importantly, we identified two metabolites (TFF3 ${ }_{7-54}$ in SGF, 275 and $\mathrm{TFF}_{7-55}$ in SIF) that remained stable even after $24 \mathrm{~h}$ 276 (Figure 4B).

277 In certain physiological environments, disulfide bonds are 278 prone to scrambling or reductive cleavage, thereby affecting 279 peptide integrity. ${ }^{67}$ Thus, we also evaluated the stability of the 280 disulfide bonds of TFF3 in the presence of 10 equivalents of 281 reduced glutathione $(\mathrm{GSH})$ at $\mathrm{pH} 7$ by time-course analytical 282 RP-HPLC. No disulfide bond reduction or scrambling was 283 observed for TFF3 or its homodimer (Figure S4) under these 284 conditions. While this was expected for the relatively buried 285 disulfide bonds within the trefoil domain $\left(\mathrm{TFF} 3_{10-50}\right)$, it 286 highlights that also the disulfide bond outside of the trefoil 287 domain is well protected.

288 We then synthesized the trefoil domain ( $T F F 3_{10-50}$, single289 chain assembly via Fmoc-SPPS) to investigate its gut stability. 290 We acetylated the $N$-terminus $\left(\mathrm{Gln}^{10}\right)$ of the trefoil domain to 291 prevent the formation of pyroglutamic acid. TFF3 ${ }_{10-50}$ was 292 stable in SGF for $24 \mathrm{~h}$ but exhibited low stability in SIF $\left(t_{1 / 2}<\right.$ $29330 \mathrm{~min}$ ) (Figure 4C). We incubated TFF3 $3_{10-50}$ with trypsin to 294 identify some of the cleavage sites and observed cleavages at $295 \mathrm{Lys}^{16}, \mathrm{Arg}^{18}$, and $\mathrm{Arg}^{41}$ and fragments $\mathrm{Glu}^{30}-\mathrm{Arg}^{34}$ and $\mathrm{Ile}^{42}$ 296 Lys $^{50}$ linked by a disulfide bond. A comparison of the NMR 297 secondary $\mathrm{H} \alpha$ chemical shifts of TFF $3_{10-50}$ with those of full298 length TFF3 (BMRB: 5771) indicated that removal of the $C$ 299 and $N$-terminal tails outside the trefoil domain did not change 300 TFF3's overall domain structure (Figure 4D).

301 We also synthesized TFF3 ${ }_{7-54}$ (single-chain assembly via 302 Fmoc-SPPS) to confirm the initial stability results and to 303 elucidate whether the residues outside the trefoil domain $304\left(\mathrm{~S}^{7} \mathrm{AN}^{9}, \mathrm{P}^{51} \mathrm{LQE}^{54}\right)$ were responsible for its greater stability. 305 TFF $_{7-54}$ was indeed stable in SGF and SIF with a half-life over $30624 \mathrm{~h}$ (Figure 4C); 25\% degradation was observed in SIF 307 within $24 \mathrm{~h}$ and MS analysis identified that cleavage mainly 308 occurred near the $C$-terminus $\left(\mathrm{Leu}^{46} / \mathrm{Gln}^{47}\right.$ and $\mathrm{Gln}^{47} / \mathrm{Glu}^{48}$ ). 309 Secondary $\mathrm{H} \alpha$ chemical shifts of $\mathrm{TFF}_{7-54}$ confirmed that it 310 had the same overall fold as full-length TFF3 (Figure 4D). $311 \mathrm{TFF}_{7-54}$ was also active in the anti-apoptosis assay, equivalent 312 to TFF3 and TFF3 homodimer (Figure 4E). Taken together, 313 these results suggest that the $N$ - and $C$-terminal extended 314 domain residues in $\mathrm{TFF}_{7-54}$ provide some steric protection 315 against intestinal proteases and that the pharmacophore sits 316 within the trefoil domain.

\section{DISCUSSION}

318 Reliable synthetic access to TFF3 and its homodimer has been 319 a long-standing challenge due to its length, difficult sequence 320 segments, disulfide-rich character, and the presence of a 321 seventh unpaired cysteine residue $\left(\mathrm{Cys}^{57}\right)$ that enables homo- or heterodimer formation. ${ }^{1,30}$ Here, we achieved the chemical 322 synthesis of the monomers TFF3 $\left(\mathrm{C}^{57} \mathrm{Acm}\right)$ and TFF3, and the 323 TFF3 homodimer (Figure 1). TFF3 $\left(\mathrm{C}^{57} \mathrm{Acm}\right)$ is a valuable 324 TFF3 analogue that cannot dimerize under physiological 325 conditions, thereby enabling a more controlled study of the 326 effects of monomeric vs homodimeric TFF3. The synthesis 327 was achieved via a combination of Fmoc-SPPS and two- 328 fragment NCL followed by an efficient oxidative folding step 329 using well-defined conditions (Figure 1). Compared to other 330 approaches (i.e., recombinant expression), our strategy has the 331 advantage of providing full control over site-specific chemical 332 modifications, being compatible with combinatorial ap- 333 proaches and facilitating the incorporation of unnatural 334 amino acids, bioconjugations handles, and reporter tags. This 335 represents therefore an important new milestone for TFF3 336 research, since it considerably expands ligand design options, 337 important for molecular probe development, structure-activity 338 relationship (SAR) studies, and therapeutic lead development. 339

TFF3's function has been associated with high metabolic 340 stability to regulate gastrointestinal protection and repair, 341 colorectal cancer development, and neuronal protection in the 342 CNS. ${ }^{1,3,30}$ However, its mechanism of action and target 343 receptors remain speculative and have not been independently 344 validated $^{1,30}$ and also the gastrointestinal stability has not been 345 systematically investigated with some studies indicating that 346 they are degraded. ${ }^{26,28}$ The presumed high gastrointestinal 347 stability of TFF $3^{68-70}$ would be an attractive feature from a 348 peptide drug development point of view, since it could enable 349 oral administration of TFF3-like drug candidates for the 350 treatment of gastrointestinal disorders. With milligram 351 quantities of TFF3 analogues at hand, we therefore 352 investigated some of these aspects further to provide novel 353 insights into TFF3's metabolic stability and mechanisms of 354 action.

355

TFF3 and its homodimer were rapidly enzymatically 356 truncated at both termini in the gastric (TFF3 $t_{1 / 2}<5 \mathrm{~min} ; 357$ TFF3 homodimer $t_{1 / 2} \sim 40 \mathrm{~min}$ ) as well as in the intestinal 358 $\left(t_{1 / 2}<5 \mathrm{~min}\right)$ environment (Figure 4A), revealing a gut-stable 359 metabolite $\left(\mathrm{TFF}_{7-54}\right.$ ) (Figure 4D). The slightly shorter trefoil 360 domain ( $\left.\mathrm{TFF} 3_{10-50}\right)$ degraded in the intestinal environment 361 $\left(t_{1 / 2}<30 \mathrm{~min}\right)$ (Figure $4 \mathrm{C}$ ), highlighting that the residues 362 $\mathrm{S}^{7} \mathrm{AN}^{9}$ and $\mathrm{P}^{51} \mathrm{LQE}^{54}$ outside the trefoil domain are important 363 for the protection against gastrointestinal degradation. The 364 metabolite $\mathrm{TFF}_{7-54}$ retained its overall three-dimensional 365 structure, including its three loops and secondary motifs 366 (Figure 4D), and displayed similar antiapoptotic activity as 367 TFF3, suggesting that TFF3's pharmacophore sits within the 368 trefoil domain. TFF3 homodimer has been reported to be 369 more potent than TFF3 in promoting cell motility, ${ }^{31,32}$ but 370 considering the rapid degradation of the homodimer, it is 371 remains questionable if it holds a major functional role in the 372 gastrointestinal environment. This aligns with TFF3 being 373 identified predominantly as a heterodimer (TFF3-FCGBP) in 374 the colon, followed by the monomeric form, and only a small 375 portion of TFF3 observed as a homodimer. ${ }^{29}$ None of the 376 metabolites have so far been reported, which is not surprising 377 considering that the methods to identify and characterize 378 TFF3 (i.e., SDS gels and antibodies) can easily miss terminal 379 truncations. $^{48,49}$ The formation of heterodimers ${ }^{29}$ and TFF3 380 binding to mucins might furthermore protect against 381 degradation. ${ }^{71}$

TFF3, TFF3 homodimer, and $\mathrm{TFF}_{7-54}$ all reduced 383 apoptosis of SH-SY5Y, a human neuroblastoma cell line 384 
385 (Figure 1), aligning well with reported antiapoptotic activity, 386 including cerebral ischemia. ${ }^{22,33,72,73}$ These antiapoptotic 387 effects support TFF3's (neuro)protective role, ${ }^{1,33,72,73}$ as well 388 as its association as a tumor growth promoter in different 389 cancers. ${ }^{8,74,75}$ TFF3 and its homodimer did not display any 390 cytotoxic or hemolytic effects, an important aspect for future 391 therapeutic development of TFF3.

392 TFF3's interaction with CXCR4, a member of the GPCR 393 family, ${ }^{58}$ was proposed to mediate cell migration via an ERK1/ 394 2-independent signaling pathway. ${ }^{39}$ This interaction was 395 established in a human conjunctival epithelial cell line 396 expressing CXCR4, where blockage of CXCR4 impaired 397 TFF3-mediated cell migration. ${ }^{39}$ While this suggests that 398 CXCR4 is involved in the mechanism of action of TFF3, it did 399 not provide evidence of direct TFF3-CXCR4 interaction. To 400 validate this interaction, we tested TFF3 and TFF3 401 homodimer in a well-established CXCR4 signaling 402 assay, $^{61-63}$ demonstrating that they neither activated nor 403 inhibited CXCR4 up to a concentration of $10 \mu \mathrm{M}$ (Figure 3D). 404 These results correspond with another study that failed to co405 localize TFF3 and CXCR4. ${ }^{38}$

406 The second putative TFF3 receptor that we investigated was 407 LINGO2, which has recently been implicated with TFF3 in 408 promoting protection against colitis in vivo. ${ }^{38}$ Neither TFF3 409 nor TFF3 homodimer displayed any effect on LINGO2 410 dimerization, which was assessed by BRET (Figure 3E). ${ }^{59}$ Due 411 to the limited availability of functional LINGO2 bioassays, we 412 cannot fully exclude that TFF3 does not signal through 413 LINGO2 and we can only state that TFF3 does not interfere 414 with dimerization.

\section{$415 \square$ CONCLUSIONS}

416 We have developed reliable synthetic strategies to produce 417 TFF3 and analogues, which will markedly facilitate mechanistic 418 and SAR studies as well as therapeutic development. We 419 revealed a gut-stable TFF3 metabolite $\left(\mathrm{TFF}_{7-54}\right)$ that retained 420 its bioactivity and demonstrated that TFF3, TFF3 homodimer, 421 and the trefoil domain $\left(\mathrm{TFF}_{10-50}\right)$ are readily degraded in the 422 gastrointestinal environment. We were not able to pharmaco423 logically confirm a TFF3 signaling or interaction with CXCR4 424 or LINGO2. The chemical synthesis of TFF3 and its 425 homodimer as well as the discovery of the truncated bioactive 426 TFF3 metabolite are important new developments for the field 427 that provide new perspectives and opportunities for the design 428 and development of advanced molecular probes and TFF3 429 analogues facilitating both fundamental research as well as 430 therapeutic development.

\section{EXPERIMENTAL SECTION}

432 Materials. Fmoc-amino acids and Fmoc-Phe-Wang Tenta Gel 433 resin (loading $0.7 \mathrm{mmol} / \mathrm{g}$ ) were purchased from Iris Biotech $\mathrm{GmbH}$ 434 (Marktredwitz, Germany). Rink amide Protide resin (loading 0.19 $435 \mathrm{mmol} / \mathrm{g}$ ) and Oxyma Pure (ethyl cyanohydroxyiminoacetate) were 436 obtained from CEM (Charlotte, NC). 2-Chlorotrityl chloride resin 437 (loading $2.0 \mathrm{mmol} / \mathrm{g}$ ) was from Chem-Impex (Wood Dale). Pepsin 438 from porcine gastric mucosa $(3500-4500$ units $/ \mathrm{mg}$ solid), hydrazine 439 hydrate and recombinant EGF (epidermal growth factor), and $N, N^{\prime}$ 440 diisopropylcarbodiimide (DIC) were from Sigma-Aldrich (Sydney, 441 Australia). $N, N$-Dimethylformamide (DMF), pancreatin from porcine 442 pancreas, trifluoroacetic acid (TFA), and diethyl ether were obtained 443 from Chem-Supply (Gillman, Australia). Trypsin-EDTA 0.25\%, 444 Dulbecco's modified Eagle's medium (DMEM), and L-glutamine 445 were from Invitrogen (Mulgrave, Australia). Fetal bovine serum 446 (FBS) was from Scientifix (South Yarra, Australia). IncuCyte caspase-
3/7 green apoptosis reagent was purchased from Essenbioscience 447 (Newark Close, U.K.). HEK-293 (ATCC CRL-1573) human 448 embryonic kidney and SH-SY5Y cells were obtained from American 449 Type Culture Collection (ATCC). Chitin beads were purchased from 450 New England Biolabs GmbH (Frankfurt, Germany). IP-One Gq assay 451 kit from CisBio (Codolet, France). Metafectene Pro was from Biontex 452 Laboratories $\mathrm{GmbH}$ (Munich, Germany). pcDNA3.1 plasmid was 453 kindly provided by Dr. Evi Kostenis, Rheinische Friedrich-Wilhelms- 454 Universität, Bonn, Germany. All solvents were obtained in the highest 455 available purity and used without further purification. All other 456 chemicals were obtained from Sigma-Aldrich/Merck (Sydney, 457 Australia) in the highest available purity. Recombinant monomeric 458 and homodimeric human TFF3 produced in yeast were kindly 459 provided by Dr. Lars Thim (Novo Nordisk A/S, Denmark). Human 460 whole blood was obtained from the Australian Red Cross Blood 461 Service.

Ethics Statement. Human ethics approval was obtained for use of 463 human blood for hemolysis studies, from the University of 464 Queensland Medical Research Ethics Committee (approval number 465 2014000031).

Peptide Synthesis. Preparation of 2-Chlorotrityl Hydrazine 467 Resin. 2-Chlorotrityl chloride resin was swelled in 50\% DMF/DCM 468 $(\mathrm{v} / \mathrm{v})$ for $30 \mathrm{~min}$ in a peptide synthesis vessel. The solution was 469 drained, and the resin was treated with $10 \%$ hydrazine hydrate/DMF 470 $(\mathrm{v} / \mathrm{v})$ for $30 \mathrm{~min}$. After draining the solution, the resin was washed 471 with DMF. Unreacted resin was capped with 5\% MeOH/DMF (v/v) 472 for $10 \mathrm{~min}$ and washed with DMF. The resin was directly used for the 473 next coupling step. Resin loading was determined by quantitative 474 Fmoc release. Briefly, 20\% piperidine/DMF was added to a $10 \mathrm{~mL} 475$ volumetric flask containing $10 \mathrm{mg}$ of dry resin and mixed for $30 \mathrm{~min} .476$ A UV cuvette was filled with $100 \mu \mathrm{L}$ of the supernatant and diluted 477 1:10 with $20 \%$ piperidine/DMF. The absorbance of the dibenzo- 478 fulvene-piperidine adduct was measured using a UV spectrometer at 479 $301 \mathrm{~nm}$. The resin loading $(\mathrm{mmol} / \mathrm{g})$ was then calculated using the 480 following formula: $A /(\mathrm{e} \times d \times m) \times 106$, where $A$ is the absorbance, $e 481$ is the extinction coefficient of dibenzofulvene adduct, $m$ is the mass of 482 resin $(\mathrm{mg})$, and $d$ is the dilution factor.

Solid-Phase Peptide Synthesis. NCL precursor peptide fragments 484 of TFF3 $\left(\mathrm{Cys}^{57}(\mathrm{Acm})\right.$ and free $\mathrm{Cys}^{57}$ forms) were synthesized on a 485 Liberty Prime automatic synthesizer (CEM, Charlotte, NC) via 486 Fmoc-SPPS on a $0.1 \mathrm{mmol}$ scale. C-terminal fragment was 487 synthesized using Fmoc-Phe-Wang (TFF3 $36-59$ ) and the hydrazide 488 fragment $\left(\mathrm{TFF}_{1-35}-\mathrm{NHNH}_{2}\right)$ on a freshly prepared 2-chlorotrityl 489 hydrazide resin. TFF $3_{10-50}$ and TFF $3_{7-54}$ were synthesized on a Rink 490 amide protide resin. Amino acid side chains were protected as follows: 491 $\operatorname{Arg}(2,2,4,6,7-$ pentamethyldihydrobenzofuran-5-sulfonyl), Asn/Gln- 492 (trityl), Asp(O-3-methylpent-3-yl), Glu(tert-butyl ester (Otbu)), 493 Cys(trityl or acetamidomethyl), His/Lys/Trp (tert-butyloxycarbonyl), 494 and $\mathrm{Ser} / \mathrm{Thr} / \mathrm{Tyr}($ tert-butyl $(t \mathrm{Bu}))$. Fmoc deprotection was per- 495 formed using 25\% pyrrolidine/DMF. Couplings (5 equiv) were 496 carried out with DIC/Oxyma Pure at $105{ }^{\circ} \mathrm{C}$. Fmoc-amino acid/ 497 DIC/Oxyma (1:2:1). Upon completion of the peptide chain, the resin 498 was washed with $\mathrm{DCM} / \mathrm{MeOH}$. Cleavage from the resin and 499 simultaneous removal of side-chain-protecting groups was achieved 500 by treatment with $90 \%$ trifluoroacetic acid (TFA) $/ 5 \%$ triisopropylsi- 501 lane (TIPS) $/ 5 \% \mathrm{H}_{2} \mathrm{O}$ at $25{ }^{\circ} \mathrm{C}$ for $90 \mathrm{~min}$. Following cleavage, the 502 solution was evaporated under a stream of $\mathrm{N}_{2}$ and the products 503 precipitated and were washed with cold $\mathrm{Et}_{2} \mathrm{O}$ and lyophilized in $50 \% 504$ acetonitrile $(\mathrm{ACN}) / 0.1 \% \mathrm{TFA} / \mathrm{H}_{2} \mathrm{O}$. The crude products were 505 purified by preparative HPLC.

Native Chemical Ligation. Only fragments with purity $>90 \%$ were 507 used for the NCL. The N-terminal fragment containing the hydrazide 508 group $(1.5 \mathrm{mM})$ was oxidized to an azide by dissolving the peptide in 509 $0.2 \mathrm{M}$ sodium phosphate buffer solution containing $6 \mathrm{M} \mathrm{Gn} \cdot \mathrm{HCl}(\mathrm{pH} 510$ 3) and reacting it with $\mathrm{NaNO}_{2}$ (10 equiv relative to the hydrazide 511 fragment) for $15 \mathrm{~min}$ at $-15{ }^{\circ} \mathrm{C}$. During this step, the C-terminal 512 fragment $(1 \mathrm{mM})$ was dissolved in $0.2 \mathrm{M}$ phosphate solution 513 containing $6 \mathrm{M} \mathrm{Gn} \cdot \mathrm{HCl}$ and sodium 2-mercaptoethanesulfonate 514 (MESNA; 100 equiv relative to the hydrazide fragment). The 515 solutions containing the peptide segments were combined, and the 516 
$517 \mathrm{pH}$ was carefully adjusted to 7.5 with $\mathrm{NaOH}$. The reaction was 518 monitored by analytical RP-HPLC and carried out for $24 \mathrm{~h}$ and 519 purified by preparative RP-HPLC. TCEP $(75 \mathrm{mM})$ was added to the 520 reaction before RP-HPLC analysis and purification.

521 Oxidative Folding. Peptides were dissolved in a minimal amount of $52250 \% \mathrm{ACN} / 0.1 \% \mathrm{TFA} / \mathrm{H}_{2} \mathrm{O}$ and added to the oxidative buffer $(0.1 \mathrm{M}$ $523 \mathrm{NH}_{4} \mathrm{HCO}_{3}$ ) for a final concentration of $50 \mu \mathrm{M}$, and the $\mathrm{pH}$ was 524 adjusted to 8.5 . Oxidation was monitored by analytical RP-HPLC and 525 electrospray mass spectroscopy (ESI-MS). After complete oxidation, 526 the $\mathrm{pH}$ was adjusted to 2 with neat TFA, filtered, and the peptide was 527 purified by preparative RP-HPLC.

528 Dimerization. Folded monomeric TFF3 with the $\mathrm{Cys}^{57}$ unpro529 tected was dissolved in $50 \% \mathrm{ACN} / 0.1 \% \mathrm{TFA} / \mathrm{H}_{2} \mathrm{O}$ to a final 530 concentration of $2.5 \mathrm{mM}$. Iodine ( 30 equiv) was added to accelerate 531 the dimerization. After complete oxidation $(2 \mathrm{~min})$, the reaction was 532 quenched with ascorbic acid and the peptide was purified by 533 preparative RP-HPLC ( $60 \%$ yield).

$534 \quad R P-H P L C$ and LC-MS Methods. Peptides were purified using either 535 a preparative $\mathrm{C}_{18}$ (Grace Vydac; $10 \mu \mathrm{m}, 2.2 \mathrm{~cm} \mathrm{ID} \times 250 \mathrm{~mm}$, flow 536 rate $15 \mathrm{~mL} / \mathrm{min}$ ) or $\mathrm{C}_{5}$ (Phenomenex Luna; $10 \mu \mathrm{m}, 21.2 \mathrm{~mm} \mathrm{ID} \times$ $537250 \mathrm{~mm}$, flow rate $15 \mathrm{~mL} / \mathrm{min}$ ) columns on a Waters $600 \mathrm{HPLC}$ 538 system (Waters Co., Milford, MA) using gradient of solvent A $(0.05 \%$ 539 TFA in water) and $\mathrm{B}\left(90 \% \mathrm{ACN} / 0.043 \% \mathrm{TFA} / 10 \% \mathrm{H}_{2} \mathrm{O}\right)$ according 540 to the peptide retention time observed by analytical RP-HPLC. $541 \mathrm{TFF}_{1-35}$ was purified using the $\mathrm{C}_{18}$ preparative RP-HPLC column 542 with a gradient of $10-40 \%$ B over $60 \mathrm{~min}$ ( $15 \%$ yield). TFF $36-59$ 543 (20\% yield) and reduced TFF3 (19\% yield) were also purified on the $544 \mathrm{C}_{18}$ preparative column with a gradient of $20-50 \% \mathrm{~B}$ over $60 \mathrm{~min}$. 545 Reduced TFF3 was washed with $10 \%$ B for 15 min before its 546 purification to remove the salts from the ligation buffer. Folded TFF3 547 was purified using the $\mathrm{C}_{5}$ preparative RP-HPLC column with a 548 gradient of $10-40 \%$ B over $60 \mathrm{~min}$. The molecular mass of the 549 fractions collected was analyzed by direct injection in an ESI-MS, and 550 those with the desired mass were further analyzed by RP-HPLC and 551 lyophilized. Peptides were analyzed by RP-HPLC using an analytical $552 \mathrm{C}_{3}$ (Agilent Zorbax SB-C $3,5 \mu \mathrm{m}, 2.1 \mathrm{~mm} \times 250 \mathrm{~mm}, 300 \AA$ ) or $\mathrm{C}_{18}$ 553 (Phenomenex Jupiter; $5 \mu \mathrm{m}, 2.1 \mathrm{~mm} \times 250 \mathrm{~mm}, 300 \AA$ ) RP-HPLC 554 column connected to a Shimadzu LC-20AT solvent delivery system 555 equipped with an SIL-20AHT autoinjector and an SPD-20A 556 Prominence ultraviolet-visible detector. Data were recorded and 557 processed with the Shimadzu LabSolutions software (version 5.90). A 558 linear gradient from 0 to $60 \%$ solvent $\mathrm{B}$ in $60 \mathrm{~min}$ was performed 559 (solvent A $0.05 \%$ TFA in water and B 90\% ACN $/ 0.043 \%$ TFA $/ 10 \%$ $560 \mathrm{H}_{2} \mathrm{O}$ ), and absorbance data were collected at $214 \mathrm{~nm}$ to determine 561 the purity of the final product. Only peptides with purity $>95 \%$ were 562 used for structural and biological analyses. The mass analysis of the 563 peptides was performed using a Q-Star Pulsar mass spectrometer 564 (SCIEX, Ontario, Canada) with a Series 1100 solvent delivery system 565 equipped with an autoinjector (Agilent Technologies, Inc., Palo Alto, $566 \mathrm{CA}$ ) and a Phenomenex Jupiter LC-MS $\mathrm{C}_{18}$ column (90 A, $4 \mu \mathrm{m}, 2$ $567 \mathrm{~mm} \times 250 \mathrm{~mm}$ ). Linear gradients of $0.1 \%$ aqueous formic acid 568 (solvent A) and $90 \% \mathrm{ACN} / 0.1 \%$ formic acid (solvent B) were 569 employed at a flow rate of $250 \mu \mathrm{L} / \mathrm{min}$, and the column was 570 maintained at $45{ }^{\circ} \mathrm{C}$. The instrument was scanned in the $\mathrm{m} / z$ range of $571500-1800 \mathrm{Da}$. Data acquisition and processing were carried out using 572 Analyst software v1.1 (SCIEX, Canada).

573 Co-elution RP-HPLC Study of TFF3 Homodimer. Synthetic and 574 recombinant homodimeric TFF3 were co-injected at a 2:1 575 (synthetic:recombinant) ratio and subjected to analytical RP-HPLC 576 analysis using a $1 \%$ solvent $\mathrm{B} / \mathrm{min}$ gradient on a $\mathrm{C}_{3}$ - $\mathrm{RP}$-HPLC 577 column (Agilent Zorbax SB-C $3,5 \mu \mathrm{m}, 2.0 \mathrm{~mm} \times 250 \mathrm{~mm}, 300 \AA$ ). 578 In Vitro Stability Assay. Simulated gastric fluid (SGF) was 579 prepared by dissolving $20 \mathrm{mg}$ of $\mathrm{NaCl}$ and $8 \mathrm{mg}$ of pepsin in 70 $580 \mu \mathrm{L}$ of concentrated $\mathrm{HCl}(32 \%)$, and the volume was diluted to $10 \mathrm{~mL}$ 581 with Milli-Q water ( $\mathrm{pH} 1.3$ ). ${ }^{76,77}$ Simulated intestinal fluid (SIF) was 582 prepared by dissolving $68 \mathrm{mg}$ of $\mathrm{KH}_{2} \mathrm{PO}_{4}$ in $500 \mu \mathrm{L}$ of Milli-Q water 583 followed by the addition of $800 \mu \mathrm{L}$ of $0.2 \mathrm{M} \mathrm{NaOH}$ and $100 \mathrm{mg}$ of 584 porcine pancreatin, and the volume was adjusted to $10 \mathrm{~mL}$ with Milli$585 \mathrm{Q}$ water ( $\mathrm{pH} \mathrm{6.8)}$. $^{76,77}$ Peptide stock solution $(1 \mathrm{mM} ; 15 \mu \mathrm{L})$ was 586 added to SGF $(285 \mu \mathrm{L})$ or SIF $(285 \mu \mathrm{L})$ and incubated at $37{ }^{\circ} \mathrm{C}$.
Samples $(30 \mu \mathrm{L})$ from SGF and SIF were taken at $0,5,15$, and 30587 min and $1,2,4,8$, and $24 \mathrm{~h}$ timepoints and subsequently quenched 588 with $30 \mu \mathrm{L}$ of $0.2 \mathrm{M} \mathrm{Na}_{2} \mathrm{CO}_{3}$ (SGF) or $30 \mu \mathrm{L}$ of $5 \%$ aqueous TFA 589 (SIF). The samples were analyzed by analytical RP-HPLC $(30 \mu \mathrm{L}) 590$ and/or LC-MS $(20 \mu \mathrm{L})$. The amount of peptide remaining was 591 determined by measuring the peak area and expressing it as a \% of the 592 peak area at time 0 . Peptide half-life $\left(t_{1 / 2}\right)$ was determined from the 593 peptide degradation profiles using an exponential one-phase decay fit 594 in Prism (version 7, GraphPad, La Jolla). LC-MS analysis was 595 performed in a Q-Star Pulsar mass spectrometer (SCIEX, Ontario, 596 Canada), and the raw data spectra were processed using the peptide 597 reconstruction tool in the BioAnalyst software to identify the mass of 598 the metabolites. The stability of the disulfide bonds was assessed 599 through incubation of the peptides $(10 \mu \mathrm{M})$ with 10 equiv of reduced 600 glutathione (GSH; $100 \mu \mathrm{M})$ in sodium phosphate $(50 \mathrm{mM})$ buffer at 601 $\mathrm{pH}$ 7.2. Samples were taken at timepoints $0,4,8$, and $24 \mathrm{~h}$, quenched 602 by adding $10 \%$ TFA, and analyzed by analytical RP-HPLC using an 603 analytical $\mathrm{C}_{3}$ column (Agilent Zorbax SB-C $3,5 \mu \mathrm{m}, 2.1 \mathrm{~mm} \times 250604$ $\mathrm{mm}, 300 \AA$ ).

605

Circular Dichroism. Stock solutions of the peptides were prepared 606 in $50 \% \mathrm{ACN} / \mathrm{H}_{2} \mathrm{O}$ at $1 \mathrm{mM}$ concentration. Peptide concentrations for 607 $\mathrm{CD}$ analysis were $50 \mu \mathrm{M}$ in $10 \mathrm{mM}$ sodium phosphate buffer $(\mathrm{pH} 608$ 7.4). CD spectra were obtained on a Jasco J-810 spectropolarimeter 609 (Easton, MD). All experiments were carried out in a $0.1 \mathrm{~cm}$ quartz 610 cell with $250 \mu \mathrm{L}$ of sample at $25{ }^{\circ} \mathrm{C}$ and examined in the far-UV 611 spectra region $(185-260 \mathrm{~nm}), 20 \mathrm{~nm} /$ min scanning speed, $1 \mathrm{~nm} 612$ bandwidth, and $0.5 \mathrm{~nm}$ data pitch with five scans averaged for each 613 sample. Blank subtraction was performed in the Spectra Management 614 Software followed by smoothening using the Savitzky-Golay method. 615 $\mathrm{CD}$ was reported as mean residue ellipticity $\left([\theta]\left(\mathrm{mdeg} \cdot \mathrm{cm}^{2} \cdot \mathrm{dmol}^{-1}\right) 616\right.$ $=(100 \times \theta) /(n \times c \times l)$, where $\theta$ is the raw output (mdeg), $n$ is the 617 number of peptide bonds, $c$ is the concentration $(\mathrm{M})$, and $l$ is the 618 cuvette path length $(\mathrm{cm}))$.

Nuclear Magnetic Resonance. NMR spectra of peptides dissolved 620 in $90 \% \mathrm{H}_{2} \mathrm{O} / 10 \% \mathrm{D}_{2} \mathrm{O}(\sim 1 \mathrm{mM})$ were recorded using a Bruker 600621 $\mathrm{MHz}$ Avance III NMR spectrometer equipped with a cryogenically 622 cooled probe (cryoprobe) at $298 \mathrm{~K}$. NOESY spectra was recorded 623 with a mixing time of $200 \mathrm{~ms}$ and TOCSY with spin lock of $80 \mathrm{~ms} .624$ Samples were internally referenced to water at $4.76 \mathrm{ppm}$. TopSpin 625 (Bruker Biospin) and CCPNMR Analysis 2.4.1 (CCPN, University of 626 Cambridge, Cambridge, U.K.) were used to process and assign the 627 spectra, respectively. NOEs in the NOESY spectrum were manually 628 picked and assigned. Secondary shifts were calculated by subtracting 629 the random coil $\mathrm{H} \alpha$ shift from the experimental $\mathrm{H} \alpha$ shifts. ${ }^{57}$

Antiapoptotic Assay. SH-SY5Y cells were seeded $\left(13-15 \times 10^{3} 631\right.$ cells/well) in 96-well microplates in DMEM with $10 \%(\mathrm{v} / \mathrm{v})$ fetal calf 632 serum (FCS; Gibco), 2 mM L-glutamine, and 100 units/mL 633 penicillin/streptomycin. The media was replaced with low riboflavin, 634 complete Ham's F12 medium with $10 \%$ (v/v) fetal calf serum, $2 \mathrm{mM} 635$ L-glutamine, and 100 units $/ \mathrm{mL}$ penicillin/streptomycin before the 636 live-cell imaging. Cells were treated with the etoposide or the caspase- 637 3 inhibitor or TFF3 monomer or homodimer in the presence of 638 IncuCyte caspase-3/7 green apoptosis reagent. Data were acquired 639 using an IncuCyte ZOOM instrument with standard scan type setting 640 (4 images per well) every $2 \mathrm{~h}$ for $48 \mathrm{~h}$.

Cell Viability/Cytotoxicity Assays. HEK-293 cells (5000 cells/ 642 well), suspended in DMEM supplemented with $10 \%$ FBS, were 643 seeded into 384-well plates in a volume of $20 \mu \mathrm{L}$. Monomeric and 644 homodimeric TFF3 were added to the cells for a final concentration 645 of $0.18-22.7 \mu \mathrm{M}$. The cell plates were then incubated for $20 \mathrm{~h}$ at 37646 ${ }^{\circ} \mathrm{C}$ and $5 \% \mathrm{CO}_{2}$. Tamoxifen was used as a positive control. After the 647 incubation, $5 \mu \mathrm{L}$ of $100 \mu \mathrm{M}$ resazurin diluted in PBS was added to 648 each well (final concentration $\sim 11 \mu \mathrm{M}$ ). The plates were then 649 incubated for $3-4 \mathrm{~h}$ at $37^{\circ} \mathrm{C}$ and $5 \% \mathrm{CO}_{2}$. The fluorescence intensity 650 (FI) was read using the TECAN Infinite M1000 PRO with 651 excitation/emission $560 / 590 \mathrm{~nm}$. Cytotoxicity or cell viability was 652 calculated using the following equation: cell viability $(\%)=\left(\mathrm{FI}_{\text {sample }}-653\right.$ $\left.\mathrm{FI}_{\text {negative }} / \mathrm{FI}_{\text {untreated }}-\mathrm{FI}_{\text {negative }}\right) \times 100 . \mathrm{CC}_{50}$ (concentration at $50 \%$ cell 654 viability) was calculated using a nonlinear regression analysis of log 655 (concentration) vs normalized cell viability. 
657 Hemolysis Analysis. Monomeric and homodimeric TFF3 were 658 serially diluted twofold in $0.9 \% \mathrm{NaCl}$ and seeded $(25 \mu \mathrm{L})$ in a $384-$ 659 well polypropylene plate $(0.2-25 \mu \mathrm{M}$ final concentration). Whole 660 blood ( $10 \mathrm{~mL} /$ tube) was washed two to three times in three volumes 661 of $0.9 \% \mathrm{NaCl}$, with centrifugation of $500 \mathrm{~g}$, with reduced deceleration, 662 for 10 min between washes. The cells were counted using a Neubauer 663 hemocytometer and then diluted to $1 \times 10^{8} / \mathrm{mL}$ in $0.9 \% \mathrm{NaCl}$. The 664 cells $(25 \mu \mathrm{L} /$ well $)$ were added to the plates containing TFF3. Melittin 665 was used as a positive control. The plates were sealed and then placed 666 on a plate shaker for $10 \mathrm{~min}$ before being incubated for $1 \mathrm{~h}$ at $37{ }^{\circ} \mathrm{C}$ 667 without shaking. Following incubation, the plates were centrifuged at $6681000 \mathrm{~g}$ for $10 \mathrm{~min}$ to pellet cells and debris and then $25 \mu \mathrm{L}$ of the 669 supernatant was transferred into a 384-well flat-bottom PS plate and 670 absorbance (Abs) was read at $405 \mathrm{~nm}$ using a Tecan M1000 Pro 671 monochromator plate reader. Percent hemolysis was calculated using 672 the following equation: Hemolysis $(\%)=\left(\mathrm{Abs}_{\text {sample }}-\mathrm{Abs}_{\text {negative }} /\right.$ $\left.673 \mathrm{Abs}_{\text {positive }}-\mathrm{Abs}_{\text {negative }}\right) \times 100 . \mathrm{HC}_{10}$ and $\mathrm{HC}_{50}$ (concentration at 10 674 and $50 \%$ hemolysis, respectively) were calculated using nonlinear 675 regression analysis of log (concentration) vs normalized hemolysis. 676 Recombinant Expression and Purification of Human CXCL12. 677 The human CXCL12 (natural CXCR4 ligand) cDNA was cloned into 678 the pTXB1 vector via Nde I and Sap I restriction sites. Generated 679 plasmids were amplified in E. coli DH5 $\alpha$ in Luria-Bertani (LB) 680 medium with $100 \mu \mathrm{g} / \mathrm{mL}$ ampicillin and purified by the PureYield 681 plasmid miniprep system (Promega $\mathrm{GmbH}$, Mannheim, Germany). 682 The correctness of the generated constructs was verified by Sanger 683 dideoxy sequencing of the entire CXCL12 sequence. CXCL12 was 684 expressed as fusion protein with a small intein domain from the 685 Mycobacterium xenopi gyrA gene and a chitin-binding domain (CBD) 686 in E. coli ER2566 in LB medium containing $100 \mu \mathrm{g} / \mathrm{mL}$ ampicillin for $6875 \mathrm{~h}$ at $37^{\circ} \mathrm{C}$ under shaking. Notably, the initial methionine, which is 688 not present in the mature human protein, is not cleaved by E. coli; 689 thus, the generated protein bears an additional $N$-terminal 690 methionine. $^{78}$ After cell lysis, and inclusion body extraction and 691 solubilization, fusion protein was purified on chitin beads and target 692 protein was eluted with column buffer $(20 \mathrm{mM}$ HEPES, $500 \mathrm{mM}$ $693 \mathrm{NaCl}, 1 \mathrm{mM}$ EDTA, $3 \mathrm{M}$ urea, $\mathrm{pH} 8$ at $4{ }^{\circ} \mathrm{C}$ ) containing $0.1 \mathrm{M}$ DTT 694 (dithiothreitol) and $0.2 \%$ Tween-20, according to the manufacturer's 695 protocol. The protein thioester was subsequently hydrolyzed under 696 basic conditions at $\mathrm{pH} 10$ and $4{ }^{\circ} \mathrm{C}$, and the target protein was 697 purified by preparative RP-HPLC on a Phenomenex Jupiter $\mathrm{C}_{18}$ 698 column $(300 \AA, 5 \mu \mathrm{m}, 250 \mathrm{~mm} \times 21.2 \mathrm{~mm}$ ) using linear gradients of $6990.1 \% \mathrm{TFA} / \mathrm{H}_{2} \mathrm{O}$ and $0.08 \% \mathrm{TFA} / \mathrm{ACN}$. The protein was restored in $7000.1 \mathrm{M} \mathrm{NaH}_{2} \mathrm{PO}_{4}, 6 \mathrm{M}$ guanidine hydrochloride, $\mathrm{pH} 6.0$, and refolded 701 by rapid dilution as described earlier. ${ }^{79}$ Finally, refolded protein was 702 isolated via preparative RP-HPLC on a Phenomenex Jupiter $\mathrm{C}_{18}$ 703 column $(300 \AA, 5 \mu \mathrm{m}, 250 \mathrm{~mm} \times 21.2 \mathrm{~mm})$ applying linear gradients 704 of $0.1 \% \mathrm{TFA} / \mathrm{H}_{2} \mathrm{O}$ and $0.08 \% \mathrm{TFA} / \mathrm{ACN}$. Identity and purity were 705 determined with ESI-/MALDI-ToF mass spectrometry (Bruker 706 Daltonik GmbH, Bremen, Germany) and analytical RP-HPLC, 707 respectively. The protein concentration was determined by photo708 metric measurement at $280 \mathrm{~nm}$ using the corresponding extinction 709 coefficient.

710 Inositol 1 Phosphate (IP1) Assay. COS-7 cells (fibroblast-like cells 711 from African green monkey) were transiently co-transfected with the 712 CXCR4 $C$-terminally fused to eYFP in pVitro2 vector and the 713 untagged chimeric $\mathrm{G}$ protein $\mathrm{G} \alpha_{\Delta 6 \mathrm{q} i 4 \mathrm{myr}}$ in pcDNA3.1 plasmid using 714 Metafectene Pro according to manufacturer's protocol. The cells were 715 cultured in DMEM with higher glucose and supplemented with $10 \%$ 716 FCS without any antibiotics at $37{ }^{\circ} \mathrm{C}$ and $5 \% \mathrm{CO}_{2}$ in $95 \%$ humidity. 717 Cisbio IP-One $\mathrm{G}_{\mathrm{q}}$ assay kit was used according to previous description 718 with minor modifications to measure activity. ${ }^{80}$ Briefly, a standard 719 curve was prepared in HBSS (Hanks' balanced salt solution) with 20 $720 \mathrm{mM} \mathrm{LiCl}$ to determine the linear range of the assay and 10000 cells/ 721 well were cultured overnight in a 384-well flat white plate (Greiner 722 Bio-one $\mathrm{GmbH}$, Frickenhausen, Germany). TFF3 and its homodimer 723 as well as CXCL12 were diluted in HBSS containing $20 \mathrm{mM} \mathrm{LiCl}$. 724 Stimulation was carried out for $1 \mathrm{~h}$ in triplicate at $37{ }^{\circ} \mathrm{C}$. 725 Subsequently, $3 \mu \mathrm{L}$ of IP1-d2 and $3 \mu \mathrm{L}$ of Ab-cryptate in lysis buffer 726 were added to the wells and incubated on a tumbler for $60 \mathrm{~min}$ at 25
${ }^{\circ} \mathrm{C}$. Fluorescence was then measured at 620 and $665 \mathrm{~nm}$ and the 727 HTRF (homogeneous time-resolved fluorescence) ratio (665/620 728 $\mathrm{nm}$ ) was calculated. Data analysis was performed with Prism (version 729 7, GraphPad, La Jolla). Tested compounds were normalized to 730 CXCL12 wild type, with the highest HTRF ratio set to $0 \%$ and the 731 lowest HTRF ratio set to $100 \%$ response. For testing the agonistic 732 activity TFF3 monomer, TFF3 homodimer and CXCL12 were 733 individually used for stimulation in the concentration range of $10^{-12} 734$ to $10^{-5} \mathrm{M}$. Antagonistic activity was tested by stimulation of the cells 735 with CXCL12 in the concentration range of $10^{-12}$ to $10^{-5} \mathrm{M}$ after 736 preincubation for $5 \mathrm{~min}$ with 1.5 -fold concentrated TFF3 or its 737 homodimer, respectively. The final concentration range of $10^{-12}$ to 738 $10^{-5} \mathrm{M}$ to CXCL12 and 1 or $10 \mu \mathrm{M}$ to TFF3 monomer and 739 homodimer was achieved by adding the compounds from a threefold 740 concentrated stock solution.

Bioluminescence Resonance Energy Transfer (BRET) Assay. 742 HEK-293 cells were cultured with $10 \%$ FBS at $37{ }^{\circ} \mathrm{C}$ and $5 \% \mathrm{CO}_{2} 743$ in DMEM for $72-96 \mathrm{~h}$. The cells were passaged to collagen- 744 pretreated $10 \mathrm{~cm}$ plates $\left(1 / 200\right.$ dilution) and incubated at $37^{\circ} \mathrm{C}$ and 745 $5 \% \mathrm{CO}_{2}$ overnight. The medium was changed $1 \mathrm{~h}$ before transfection. 746 BRET assays were performed following transient transfection of the 747 donor protein (LINGO2-RLuc) alone or with the acceptor protein 748 (LINGO2-YFP) using the calcium phosphate method. The cells were 749 rinsed twice with sterile PBS $1 \times$ and incubated in fresh DMEM with 750 $10 \%$ FBS at $37{ }^{\circ} \mathrm{C}$ and $5 \% \mathrm{CO}_{2}$ overnight 1 day after transfection. 751 Following $48 \mathrm{~h}$ of transfection, the medium was removed and the cells 752 were rinsed twice with PBS $1 \times$ and harvested with $10 \mathrm{~mL}$ of HBSS at 753 $25{ }^{\circ} \mathrm{C}$. The cell suspension was seeded in quadruplets in a 96-well 754 plate $(\sim 10000$ cells/well $)$ in which different concentrations of 755 monomeric and homodimeric TFF3 have been loaded. After 20 min 756 incubation, the fluorescence was measured on a Mithras LB 940757 Multimode Microplate Reader (Berthold Technologies, Germany) to 758 check if the peptides alone did not modify fluorescent emission of 759 YFP following excitation at $485 \mathrm{~nm}$ and reading at $530 \mathrm{~nm}$. Then, 760 total luminescence was measured by following coelenterazine addition 761 (final concentration $5 \mu \mathrm{M}$ ). BRET signal was measured in four 762 repeats and calculated by determining the emission ratio at 530/480 763 $\mathrm{nm}$ on cells coexpressing donor and acceptor and by subtracting the 764 emission background BRET signal ratio $(530 / 480 \mathrm{~nm})$ of cells 765 expressing only donor protein, then multiplying by 1,000 to obtain 766 results in millBRET units $(\mathrm{mBU})$.

\section{ASSOCIATED CONTENT}

\section{Supporting Information}

768 https://pubs.acs.org/doi/10.1021/acs.jmedchem.1c00767. 771

Oxidative folding of TFF3, analytical HPLC and high- 772 resolution $\mathrm{MS}$ traces of $\mathrm{TFF} 3\left(\mathrm{C}^{57} \mathrm{Acm}\right)$ chemical 773 synthesis, analytical HPLC profile of TFF3, and stability 774 of TFF3 disulfide bonds (PDF)

Molecular formula strings (CSV)

\section{AUTHOR INFORMATION}

\section{Corresponding Author}

Markus Muttenthaler - Institute for Molecular Bioscience, 779 The University of Queensland, Brisbane, QLD 4072, $\quad 780$ Australia; Institute of Biological Chemistry, Faculty of 781 Chemistry, University of Vienna, 1090 Vienna, Austria; 782 ๑ orcid.org/0000-0003-1996-4646; Phone: (+43) 14277783 70515; Email: markus.muttenthaler@univie.ac.at

\section{Authors}

Nayara Braga Emidio - Institute for Molecular Bioscience, 786 The University of Queensland, Brisbane, QLD 4072, $\quad 787$ Australia; 1 orcid.org/0000-0001-7835-9636 788

Rajeshwari Meli - Institute of Biological Chemistry, Faculty of 789 Chemistry, University of Vienna, 1090 Vienna, Austria

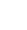
(1) .

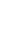


815 Complete contact information is available at: 816 https://pubs.acs.org/10.1021/acs.jmedchem.1c00767

\section{Author Contributions}

818 N.B.E., C.I.S., and M.M. conceived the idea. N.B.E., M.M., and 819 C.I.S. designed and supervised the experiments. N.B.E. and 820 H.N.T.T. performed chemical synthesis and gastrointestinal 821 stability assays. N.B.E. and C.I.S. performed structural analysis. 822 N.B.E. and H.B. carried out migration, and R.M. performed 823 anti-apoptosis assays. S.M.-L. performed the BRET assay. 824 M.A.T.B. and A.G.E. carried out the cytotoxicity and hemolysis 825 assays. S.S. performed and A.G.B.-S. supervised the CXCR4 826 assays. N.B.E. analyzed the data and wrote the manuscript. All 827 authors discussed the data, provided critical feedback, and 828 commented on the manuscript. The manuscript was written 829 through contributions of all authors. All authors have given 830 approval to the final version of the manuscript.

\section{Notes}

832 The authors declare no competing financial interest.

\section{ACKNOWLEDGMENTS}

834 M.M. was supported by the European Research Council 835 (ERC) under the European Union's Horizon 2020 research 836 and innovation program (714366) and by the Australian 837 Research Council (ARC) (DE150100784, DP190101667). 838 C.I.S. was an ARC Future Fellow (FT160100055). R.M. was 839 supported by the Austrian Science Fund (FWF) and Hertha 840 Firnberg program (T948-B27). N.B.E. was supported by the 841 University of Queensland International Postgraduate Scholar842 ship. The authors thank Janet Reid and CO-ADD (the 843 Community for Open Antimicrobial Drug Discovery), funded 844 by the Wellcome Trust (Strategic Award 104797/Z/14/Z) 845 and the University of Queensland, for the cytotoxicity and 846 hemolysis assays. They thank Dr. Lars Thim (Novo Nordisk $847 \mathrm{~A} / \mathrm{S}$ ) for providing the recombinant TFF3, and Prof. Paul 848 Alewood (The University of Queensland) for his overall 849 support of this work.

\section{ABBREVIATIONS}

BRET, bioluminescence resonance energy transfer; $\mathrm{CD}, 851$ circular dichroism; CXCL12, C-X-C motif chemokine 12; 852 CXCR4, chemokine receptor type 4; CNS, central nervous 853 system; EGFR, enhanced epidermal growth factor receptor; 854 FCGBP, Fc fragment of IgG Fc binding protein; Fmoc-SPPS, 855 9-fluorenymethyloxycarbonyl-solid-phase peptide synthesis; 856 GSH, reduced glutathione; HEK-293, human embryonic 857 kidney 293; IBD, inflammatory bowel diseases; LINGO2, 858 leucine-rich repeat receptor and nogo-interacting protein 2; 859 MESNA, sodium 2-mercaptoethanesulfonate; NOESY, nuclear 860 Overhauser effect spectroscopy; NMR, nuclear magnetic 861 resonance; SGF, simulated gastric fluid; SIF, simulated 862 intestinal fluid; TOCSY, total correlation spectroscopy 863

\section{REFERENCES}

(1) Braga Emidio, N.; Brierley, S. M.; Schroeder, C. I.; Muttenthaler, 865 M. Structure, function, and therapeutic potential of the trefoil factor 866 family in the gastrointestinal tract. ACS Pharmacol. Transl. Sci. 2020, 867 3, 583-597.

(2) Taupin, D.; Podolsky, D. K. Trefoil factors: Initiators of mucosal 869 healing. Nat. Rev. Mol. Cell Biol. 2003, 4, 721.

(3) Thim, L.; May, F. E. B. Structure of mammalian trefoil factors 871 and functional insights. Cell. Mol. Life Sci. 2005, 62, 2956-2973. 872

(4) Aihara, E.; Engevik, K. A.; Montrose, M. H. Trefoil factor 873 peptides and gastrointestinal function. Annu. Rev. Physiol. 2017, 79, 874 357-380.

875

(5) Dignass, A.; Lynch-Devaney, K.; Kindon, H.; Thim, L.; 876 Podolsky, D. K. Trefoil peptides promote epithelial migration through 877 a transforming growth factor beta-independent pathway. J. Clin. Invest. 878 1994, 94, 376-383.

(6) Hoffmann, W.; Jagla, W.; Wiede, A. Molecular medicine of TFF- 880 peptides: from gut to brain. Histol. Histopathol. 2001, 16, 319-334. 881

(7) Schwarz, H.; Jagla, W.; Wiede, A.; Hoffmann, W. Ultrastructural 882 co-localization of TFF3-peptide and oxytocin in the neural lobe of the 883 porcine pituitary. Cell Tissue Res. 2001, 305, 411-416. 884

(8) Perry, J. K.; Kannan, N.; Grandison, P. M.; Mitchell, M. D.; 885 Lobie, P. E. Are trefoil factors oncogenic? Trends Endocrinol. Metab. 886 2008, 19, 74-81.

(9) Jahan, R.; Shah, A.; Kisling, S. G.; Macha, M. A.; Thayer, S.; 888 Batra, S. K.; Kaur, S. Odyssey of trefoil factors in cancer: diagnostic 889 and therapeutic implications. BBA, Biochim. Biophys. Acta, Rev. Cancer 890 2020, No. 188362.

(10) Madsen, J.; Nielsen, O.; Tornoe, I.; Thim, L.; Holmskov, U. 892 Tissue localization of human trefoil factors 1, 2, and 3. J. Histochem. 893 Cytochem. 2007, 55, 505-513.

(11) Mashimo, H.; Wu, D. C.; Podolsky, D. K.; Fishman, M. C. 895 Impaired defense of intestinal mucosa in mice lacking intestinal trefoil 896 factor. Science 1996, 274, 262-265.

(12) Farrell, J. J.; Taupin, D.; Koh, T. J.; Chen, D.; Zhao, C. M.; 898 Podolsky, D. K.; Wang, T. C. TFF2/SP-deficient mice show 899 decreased gastric proliferation, increased acid secretion, and increased 900 susceptibility to NSAID injury. J. Clin. Invest. 2002, 109, 193-204. 901 (13) Guppy, N. J.; El-Bahrawy, M. E.; Kocher, H. M.; Fritsch, K.; 902 Qureshi, Y. A.; Poulsom, R.; Jeffery, R. E.; Wright, N. A.; Otto, W. R.; 903 Alison, M. R. Trefoil factor family peptides in normal and diseased 904 human pancreas. Pancreas 2012, 41, 888-896.

(14) Longman, R. J.; Douthwaite, J.; Sylvester, P. A.; Poulsom, R.; 906 Corfield, A. P.; Thomas, M. G.; Wright, N. A. Coordinated 907 localisation of mucins and trefoil peptides in the ulcer associated 908 cell lineage and the gastrointestinal mucosa. Gut 2000, 47, 792-800. 909

(15) Alison, M. R.; Chinery, R.; Poulsom, R.; Ashwood, P.; 910 Longcroft, J. M.; Wright, N. A. Experimental ulceration leads to 911 sequential expression of spasmolytic polypeptide, intestinal trefoil 912 factor, epidermal growth-factor and transforming growth-factor-alpha 913 messenger-RNAs in rat stomach. J. Pathol. 1995, 175, 405-414. 914 
915 (16) Aamann, L.; Vestergaard, E. M.; Groenbaek, H. Trefoil factors 916 in inflammatory bowel disease. World J. Gastroenterol. 2014, 20, $9173223-3230$.

918 (17) Furuta, G. T.; Turner, J. R.; Taylor, C. T.; Hershberg, R. M.; 919 Comerford, K.; Narravula, S.; Podolsky, D. K.; Colgan, S. P. Hypoxia920 inducible factor 1-dependent induction of intestinal trefoil factor 921 protects barrier function during hypoxia. J. Exp. Med. 2001, 193, 922 1027-1034.

923 (18) Arnold, P.; Rickert, U.; Helmers, A. K.; Spreu, J.; 924 Schneppenheim, J.; Lucius, R. Trefoil factor 3 shows anti925 inflammatory effects on activated microglia. Cell Tissue Res. 2016, 926 365, 3-11.

927 (19) Shi, H. S.; Yin, X.; Song, L.; Guo, Q. J.; Luo, X. H. 928 Neuropeptide Trefoil factor 3 improves learning and retention of 929 novel object recognition memory in mice. Behav. Brain Res. 2012, $930227,265-269$.

931 (20) Shi, H. S.; Zhu, W. L.; Liu, J. F.; Luo, Y. X.; Si, J. J.; Wang, S. J.; 932 Xue, Y. X.; Ding, Z. B.; Shi, J.; Lu, L. PI3K/Akt signaling pathway in 933 the basolateral amygdala mediates the rapid antidepressant-like effects 934 of trefoil factor 3. Neuropsychopharmacology 2012, 37, 2671-2683. 935 (21) Li, J. L.; Luo, Y. X.; Zhang, R. X.; Shi, H. S.; Zhu, W. L.; Shi, J. 936 Neuropeptide trefoil factor 3 reverses depressive-like behaviors by 937 activation of BDNF-ERK-CREB signaling in olfactory bulbectomized 938 rats. Int. J. Mol. Sci. 2015, 16, 28386-28400.

939 (22) Liu, S. Q.; Roberts, D.; Zhang, B.; Ren, Y. P.; Zhang, L. Q.; Wu, 940 Y. H. Trefoil Factor 3 as an Endocrine Neuroprotective Factor from 941 the Liver in Experimental Cerebral Ischemia/Reperfusion Injury. 942 PLoS One 2013, 8, e77732.

943 (23) Hoffmann, W. TFF Peptides. In Handbook of Biologically Active 944 Peptides, Second ed.; Academic Press, 2013; pp 1338-1345.

945 (24) Lemercinier, X.; Muskett, F. W.; Cheeseman, B.; McIntosh, P. 946 B.; Thim, L.; Carr, M. D. High-resolution solution structure of human 947 intestinal trefoil factor and functional insights from detailed structural 948 comparisons with the other members of the trefoil family of 949 mammalian cell motility factors. Biochemistry 2001, 40, 9552-9559. 950 (25) Taupin, D.; Podolsky, D. K. Trefoil factors: initiators of 951 mucosal healing. Nat. Rev. Mol. Cell. Biol. 2003, 4, 721-732.

952 (26) Poulsen, S. S.; Thulesen, J.; Hartmann, B.; Kissow, H. L.; Nexo, 953 E.; Thim, L. Injected TFF1 and TFF3 bind to TFF2-immunoreactive 954 cells in the gastrointestinal tract in rats. Regul. Pept. 2003, 115, 91-99. 955 (27) Kjellev, S.; Vestergaard, E. M.; Nexo, E.; Thygesen, P.; Ehoj, M. 956 S.; Jeppesen, P. B.; Thim, L.; Pedersen, N. B.; Poulsen, S. S. 957 Pharmacokinetics of trefoil peptides and their stability in gastro958 intestinal contents. Peptides 2007, 28, 1197-1206.

959 (28) Houben, T.; Harder, S.; Schlüter, H.; Kalbacher, H.; Hoffmann, $960 \mathrm{~W}$. Different forms of TFF3 in the human saliva: heterodimerization 961 with IgG Fc binding protein (FCGBP). Int. J. Mol. Sci. 2019, 20, 5000. 962 (29) Albert, T. K.; Laubinger, W.; Muller, S.; Hanisch, F. G.; 963 Kalinski, T.; Meyer, F.; Hoffmann, W. Human intestinal TFF3 forms 964 disulfide-linked heteromers with the mucus-associated FCGBP 965 protein and is released by hydrogen sulfide. J. Proteome Res. 2010, 966 9, 3108-3117.

967 (30) Braga Emidio, N.; Hoffmann, W.; Brierley, S. M.; Muttenthaler, $968 \mathrm{M}$. Trefoil factor family: unresolved questions and clinical 969 perspectives. Trends Biochem. Sci. 2019, 44, 387-390.

970 (31) Marchbank, T.; Westley, B. R.; May, F. E. B.; Calnan, D. P.; 971 Playford, R. J. Dimerization of human pS2 (TFF1) plays a key role in 972 its protective/healing effects. J. Pathol. 1998, 185, 153-158.

973 (32) Poulsen, S. S.; Kissow, H.; Hare, K.; Hartmann, B.; Thim, L. 974 Luminal and parenteral TFF2 and TFF3 dimer and monomer in two 975 models of experimental colitis in the rat. Regul. Pept. 2005, 126, 163976171.

977 (33) Taupin, D. R.; Kinoshita, K.; Podolsky, D. K. Intestinal trefoil 978 factor confers colonic epithelial resistance to apoptosis. Proc. Natl. 979 Acad. Sci. U.S.A. 2000, 97, 799-804.

980 (34) Chen, Y. H.; Lu, Y.; De Plaen, I. G.; Wang, L. Y.; Tan, X. D. 981 Transcription factor NF-kappa B signals antianoikic function of trefoil 982 factor 3 on intestinal epithelial cells. Biochem. Biophys. Res. Commun. 983 2000, 274, 576-582.
(35) Chinery, R.; Playford, R. J. Combined intestinal trefoil factor 984 and epidermal growth-factor is prophylactic against indomethacin- 985 induced gastric damage in the rat. Clin. Sci. 1995, 88, 401-403. 986 (36) Dürer, U.; Hartig, R.; Bang, S.; Thim, L.; Hoffmann, W. TFF3 987 and EGF induce different migration patterns of intestinal epithelial 988 cells in vitro and trigger increased internalization of E-cadherin. Cell 989 Physiol. Biochem. 2007, 20, 329-346.

990

(37) Duraj-Thatte, A. M.; Praveschotinunt, P.; Nash, T. R.; Ward, F. 991 R.; Joshi, N. S. Modulating bacterial and gut mucosal interactions with 992 engineered biofilm matrix proteins. Sci. Rep. 2018, 8, No. 3475. 993 (38) Belle, N. M.; Ji, Y.; Herbine, K.; Wei, Y.; Park, J.; Zullo, K.; 994 Hung, L. Y.; Srivatsa, S.; Young, T.; Oniskey, T.; Pastore, C.; Nieves, 995 W.; Somsouk, M.; Herbert, D. R. TFF3 interacts with LINGO2 to 996 regulate EGFR activation for protection against colitis and gastro- 997 intestinal helminths. Nat. Commun. 2019, 10, No. 4408.

(39) Dieckow, J.; Brandt, W.; Hattermann, K.; Mentlein, R.; Schob, 999 S.; Schulze, U.; Ackermann, P.; Sel, S.; Paulsen Friedrich, P. CXCR4 1000 and CXCR7 mediate TFF3-induced cell migration independently 1001 from the ERK1/2 signaling pathway. Invest. Ophthalmol. Visual Sci. 1002 2016, 57, 56-65.

1003

(40) Vandenbroucke, K.; Hans, W.; Van Huysse, J.; Neirynck, S.; 1004 Demetter, P.; Remaut, E.; Rottiers, P.; Steidler, L. Active delivery of 1005 trefoil factors by genetically modified Lactococcus lactis prevents and 1006 heals acute colitis in mice. Gastroenterology 2004, 127, 502-513. 1007

(41) Tran, C. P.; Cook, G. A.; Yeomans, N. D.; Thim, L.; Giraud, A. 1008 S. Trefoil peptide TFF2 (spasmolytic polypeptide) potently 1009 accelerates healing and reduces inflammation in a rat model of 1010 colitis. Gut 1999, 44, 636-642.

1011

(42) Babyatsky, M. W.; deBeaumont, M.; Thim, L.; Podolsky, D. K. 1012 Oral trefoil peptides protect against ethanol- and indomethacin- 1013 induced gastric injury in rats. Gastroenterology 1996, 110, 489-497. 1014 (43) Mahmood, A.; Melley, L.; Fitzgerald, A. J.; Ghosh, S.; Playford, 1015 R. J. Trial of trefoil factor 3 enemas, in combination with oral 5- 1016 aminosalicylic acid, for the treatment of mild-to-moderate left-sided 1017 ulcerative colitis. Aliment. Pharmacol. Ther. 2005, 21, 1357-1364. 1018 (44) Peterson, D. E.; Barker, N. P.; Akhmadullina, L. I.; Rodionova, 1019 I.; Sherman, N. Z.; Davidenko, I. S.; Rakovskaya, G. N.; Gotovkin, E. 1020 A.; Shinkarev, S. A.; Kopp, M. V.; Kulikov, E. P.; Moiseyenko, V. M.; 1021 Gertner, J. M.; Firsov, I.; Tuleneva, T.; Yarosh, A.; Woon, C. W. 1022 Phase II, randomized, double-blind, placebo-controlled study of 1023 recombinant human intestinal trefoil factor oral spray for prevention 1024 of oral mucositis in patients with colorectal cancer who are receiving 1025 fluorouracil-based chemotherapy. J. Clin. Oncol. 2009, 27, 4333- 1026 4338.

1027

(45) Thim, L.; Woldike, H. F.; Nielsen, P. F.; Christensen, M.; 1028 Lynchdevaney, K.; Podolsky, D. K. Characterization of human and rat 1029 intestinal trefoil factor produced in yeast. Biochemistry 1995, 34, 1030 $4757-4764$.

1031

(46) Wang, H. B.; Tong, Y. P.; Fang, M.; Ru, B. G. High-level 1032 expression of human TFF3 in Escherichia coli. Peptides 2005, 26, 1033 $1213-1218$.

1034

(47) Le, J.; Zhang, D. Y.; Zhao, Y.; Qiu, W.; Wang, P.; Sun, Y. ITF 1035 promotes migration of intestinal epithelial cells through crosstalk 1036 between the ERK and JAK/STAT3 pathways. Sci. Rep. 2016, 6, 1037 No. 33014.

1038

(48) Barrera, G. J.; Sanchez, G.; Gonzalez, J. E. Trefoil factor 31039 isolated from human breast milk downregulates cytokines (IL8 and 1040 IL6) and promotes human beta defensin (hBD2 and hBD4) 1041 expression in intestinal epithelial cells HT-29. Bosnian J. Basic. Med. 1042 Sci. 2012, 12, 256-264.

1043

(49) Yu, K.; Jiang, S. F.; Lin, M. F.; Wu, J. B.; Lin, J. Extraction and 1044 purification of biologically active intestinal trefoil factor from human 1045 meconium. Lab. Invest. 2004, 84, 390-392.

1046

(50) Zheng, J. S.; Tang, S.; Qi, Y. K.; Wang, Z. P.; Liu, L. Chemical 1047 synthesis of proteins using peptide hydrazides as thioester surrogates. 1048 Nat. Protoc. 2013, 8, 2483-2495.

1049

(51) Luo, H. B.; Cao, M. Y.; Newell, K.; Afdahl, C.; Wang, J.; Wang, 1050 W. K.; Li, Y. L. Double-peak elution profile of a monoclonal antibody 1051 in cation exchange chromatography is caused by histidine- 1052 
1053 protonation-based charge variants. J. Chromatogr. A 2015, 1424, 921054101.

1055 (52) Cardoso, F. C.; Dekan, Z.; Smith, J. J.; Deuis, J. R.; Vetter, I.; 1056 Herzig, V.; Alewood, P. F.; King, G. F.; Lewis, R. J. Modulatory 1057 features of the novel spider toxin mu-TRTX-Dfla isolated from the 1058 venom of the spider Davus fasciatus. Br. J. Pharmacol. 2017, 174, 1059 2528-2544.

1060 (53) Wingerd, J. S.; Mozar, C. A.; Ussing, C. A.; Murali, S. S.; Chin, 1061 Y. K.; Cristofori-Armstrong, B.; Durek, T.; Gilchrist, J.; Vaughan, C. 1062 W.; Bosmans, F.; Adams, D. J.; Lewis, R. J.; Alewood, P. F.; Mobli, 1063 M.; Christie, M. J.; Rash, L. D. The tarantula toxin beta/delta-TRTX1064 Pre1a highlights the importance of the S1-S2 voltage-sensor region for 1065 sodium channel subtype selectivity. Sci. Rep. 2017, 7, No. 974.

1066 (54) Takahashi, H.; Kim, J. I.; Min, H. J.; Sato, K.; Swartz, K. J.; 1067 Shimada, I. Solution structure of hanatoxin1, a gating modifier of 1068 voltage-dependent $\mathrm{K}(+)$ channels: common surface features of gating 1069 modifier toxins. J. Mol. Biol. 2000, 297, 771-780.

1070 (55) Braga Emidio, N.; Baik, H.; Lee, D.; Sturmer, R.; Heuer, J.; 1071 Elliott, A. G.; Blaskovich, M. A. T.; Haupenthal, K.; Tegtmeyer, N.; 1072 Hoffmann, W.; Schroeder, C. I.; Muttenthaler, M. Chemical synthesis 1073 of human trefoil factor 1 (TFF1) and its homodimer provides novel 1074 insights into their mechanisms of action. Chem. Commun. 2020, 56, 1075 6420-6423.

1076 (56) Muskett, F. W.; May, F. E. B.; Westley, B. R.; Feeney, J. 1077 Solution structure of the disulfide-linked dimer of human intestinal 1078 trefoil factor (TFF3): the intermolecular orientation and interactions 1079 are markedly different from those of other dimeric trefoil protein. 1080 Biochemistry 2003, 42, 15139-15147.

1081 (57) Wishart, D. S.; Bigam, C. G.; Holm, A.; Hodges, R. S.; Sykes, B. $1082 \mathrm{D} .1 \mathrm{H}, 13 \mathrm{C}$ and $15 \mathrm{~N}$ random coil NMR chemical shifts of the 1083 common amino acids. I. Investigations of nearest-neighbor effects. J. 1084 Biomol. NMR 1995, 5, 67-81.

1085 (58) Lefrançois, M.; Lefebvre, M. R.; Saint-Onge, G.; Boulais, P. E.; 1086 Lamothe, S.; Leduc, R.; Lavigne, P.; Heveker, N.; Escher, E. Agonists 1087 for the Chemokine Receptor CXCR4. ACS Med. Chem. Lett. 2011, 2, 1088 597-602.

1089 (59) Guillemain, A.; Laouarem, Y.; Cobret, L.; Stefok, D.; Chen, W. 1090 Y.; Bloch, S.; Zahaf, A.; Blot, L.; Reverchon, F.; Normand, T.; 1091 Decoville, M.; Grillon, C.; Traiffort, E.; Morisset-Lopez, S. LINGO 1092 family receptors are differentially expressed in the mouse brain and 1093 form native multimeric complexes. FASEB J. 2020, 34, 13641-13653. 1094 (60) Czekanska, E. M. Assessment of cell proliferation with 1095 resazurin-based fluorescent dye. In Methods in Molecular Biology; 1096 Humana Press, 2011; Vol. 740, pp 27-32.

1097 (61) Kostenis, E. Potentiation of GPCR-signaling via membrane 1098 targeting of G protein alpha subunits. J. Recept. Signal Transduction 1099 Res. 2002, 22, 267-281.

1100 (62) Berridge, M. J. Rapid accumulation of inositol trisphosphate 1101 reveals that agonists hydrolyze polyphosphoinositides instead of 1102 phosphatidylinositol. Biochem. J. 1983, 212, 849-858.

1103 (63) Berridge, M. J.; Dawson, R. M. C.; Downes, C. P.; Heslop, J. P.; 1104 Irvine, R. F. Changes in the levels of inositol phosphates after agonist1105 dependent hydrolysis of membrane phosphoinositides. Biochem. J. 1106 1983, 212, 473-482.

1107 (64) Degorce, F.; Card, A.; Soh, S.; Trinquet, E.; Knapik, G. P.; Xie, 1108 B. HTRF: A technology tailored for drug discovery - a review of 1109 theoretical aspects and recent applications. Curr. Chem. Genomics 1110 2009, 3, 22-32.

1111 (65) El Khamlichi, C.; Reverchon-Assadi, F.; Hervouet-Coste, N.; 1112 Blot, L.; Reiter, E.; Morisset-Lopez, S. Bioluminescence resonance 1113 energy transfer as a method to study protein-protein interactions: 1114 application to $G$ protein coupled receptor biology. Molecules 2019, 24, 1115537.

1116 (66) Qi, G. F.; Li, J. J.; Wang, S. Y.; Xin, S. S.; Du, P.; Zhang, Q. Y.; 1117 Zhao, X. Y. A chimeric peptide of intestinal trefoil factor containing 1118 cholesteryl ester transfer protein B cell epitope significantly inhibits 1119 atherosclerosis in rabbits after oral administration. Peptides 2011, 32, $1120790-796$.
(67) Räder, A. F. B.; Weinmuller, M.; Reichart, F.; Schumacher- 1121 Klinger, A.; Merzbach, S.; Gilon, C.; Hoffman, A.; Kessler, H. Orally 1122 active peptides: is there a magic bullet? Angew. Chem., Int. Ed. 2018, 1123 57, 14414-14438.

1124

(68) Jørgensen, K. H.; Thim, L.; Jacobsen, H. E. Pancreatic 1125 spasmolytic polypeptide (PSP): I. preparation and initial chemical 1126 characterization of a new polypeptide from porcine pancreas. Regul. 1127 Pept. 1982, 3, 207-219.

(69) Playford, R. J.; Marchbank, T.; Chinery, R.; Evison, R.; 1129 Pignatelli, M.; Boulton, R. A.; Thim, L.; Hanby, A. M. Human 1130 spasmolytic polypeptide is a cytoprotective agent that stimulates cell- 1131 migration. Gastroenterology 1995, 108, 108-116.

1132

(70) Sun, Y.; Peng, X.; Zhang, Y.; Lv, S. J.; Wu, W.; Wang, S. L. 1133 Stability and biological activity of human intestinal trefoil factor 1134 produced by Pichia pastoris. Protein Pept. Lett. 2008, 15, 255-259. 1135 (71) Yu, H.; He, Y.; Zhang, X.; Peng, Z.; Yang, Y.; Zhu, R.; Bai, J.; 1136 Tian, Y.; Li, X.; Chen, W.; Fang, D.; Wang, R. The rat IgGFc $\gamma B P$ and 1137 MUC2 C-terminal domains and TFF3 in two intestinal mucus layers 1138 bind together by covalent interaction. PLoS One 2011, 6, No. e20334. 1139

(72) Kinoshita, K.; Taupin, D. R.; Itoh, H.; Podolsky, D. K. Distinct 1140 pathways of cell migration and antiapoptotic response to epithelial 1141 injury: structure-function analysis of human intestinal trefoil factor. 1142 Mol. Cell. Biol. 2000, 20, 4680-4690.

1143

(73) Sun, Z. R.; Liu, H. M.; Yang, Z. Z.; Shao, D. B.; Zhang, W.; 1144 Ren, Y.; Sun, B. D.; Lin, J. F.; Xu, M.; Nie, S. N. Intestinal trefoil 1145 factor activates the PI3K/Akt signaling pathway to protect gastric 1146 mucosal epithelium from damage. Int. J. Oncol. 2014, 45, 1123-1132. 1147 (74) Hanisch, C.; Sharbati, J.; Kutz-Lohroff, B.; Huber, O.; 1148 Einspanier, R.; Sharbati, S. TFF3-dependent resistance of human 1149 colorectal adenocarcinoma cells HT-29/B6 to apoptosis is mediated 1150 by miR-491-5p regulation of IncRNA PRINS. Cell Death Discovery 1151 2017, 3, No. 16106.

1152

(75) Liu, J.; Kim, S. Y.; Shin, S.; Jung, S.-H.; Yim, S.-H.; Lee, J. Y.; 1153 Lee, S.-H.; Chung, Y.-J. Overexpression of TFF3 is involved in 1154 prostate carcinogenesis via blocking mitochondria-mediated apopto- 1155 sis. Exp. Mol. Med. 2018, 50, 1-11.

1156

(76) Wang, J.; Yadav, V.; Smart, A. L.; Tajiri, S.; Basit, A. W. Toward 1157 oral delivery of biopharmaceuticals: an assessment of the gastro- 1158 intestinal stability of 17 peptide drugs. Mol. Pharmaceutics 2015, 12, 1159 966-973.

1160

(77) Braga Emidio, N.; Tran, H. N. T.; Andersson, A.; Dawson, P. 1161 E.; Albericio, F.; Vetter, I.; Muttenthaler, M. Improving the 1162 gastrointestinal stability of linaclotide. J. Med. Chem. 2021, 1163 DOI: 10.1021 /acs.jmedchem.1c00380.

1164

(78) Hirel, P. H.; Schmitter, J. M.; Dessen, P.; Fayat, G.; Blanquet, S. 1165 Extent of N-terminal methionine excision from Escherichia coli 1166 proteins is governed by the side-chain length of the penultimate 1167 amino-acid. Proc. Natl. Acad. Sci. U.S.A. 1989, 86, 8247-8251. 1168 (79) Baumann, L.; Prokoph, S.; Gabriel, C.; Freudenberg, U.; 1169 Werner, C.; Beck-Sickinger, A. G. A novel, biased-like SDF-1 1170 derivative acts synergistically with starPEG-based heparin hydrogels 1171 and improves eEPC migration in vitro. J. Controlled Release 2012, 162, 1172 $68-75$.

1173

(80) Wanka, L.; Babilon, S.; Kaiser, A.; Mörl, K.; Beck-Sickinger, A. 1174 G. Different mode of arrestin-3 binding at the human Y1 and Y2 1175 receptor. Cell. Signalling 2018, 50, 58-71. 